\title{
Static behaviour of two-directional functionally graded sandwich beams using various beam theories
}

\author{
Armagan Karamanli \\ Department of Mechatronics, Faculty of Engineering and Architecture, Istanbul Gelisim University, Istanbul, Turkey \\ Received: 31 November 2016, Accepted: 27 February 2017 \\ Published online: 2 May 2017.
}

\begin{abstract}
This paper presents the static behaviour of two-directional functionally graded sandwich beams by using the Euler-Bernoulli, Timoshenko and Reddy-Bickford beam theories and the Symmetric Smoothed Particle Hydrodynamics (SSPH) method. The SSPH code developed based on the present formulation of the functionally graded sandwich beam is validated by solving a simply supported conventional functionally graded beam problem. Numerical results which are in terms of maximum dimensionless transverse deflections, dimensionless axial and transverse shear stresses are compared with the analytical solutions and the results from previous studies. Various FG sandwich beam structures are investigated by considering different beam theories, aspect ratios $(\mathrm{L} / \mathrm{h})$ and sets of boundary conditions and using power-law distribution.
\end{abstract}

Keywords: Meshless method, element free, functionally graded sandwich beam, SSPH method, Shear deformation theories.

\section{Introduction}

In recent years, the use of the structures which are made of functionally graded materials (FGM) have been increasing in many modern engineering applications such as aerospace, marine, automotive, nuclear energy, biomedical and civil engineering due to varying material properties over a changing dimension which allow to enhance the bond strength through the layer interfaces, high resistance to temperature shocks, lower transverse shear stresses and high strength to weigth ratio.

Researchers have been devoted a considerable number of studies to predict and to understand the mechanics of the 1D-FGM and 2D-FGM structures structures during the last decade [1-48].

As it is seen from above literature survey, the studies related to analytical and semi-analytical solutions for the 2D-FGM structures which eliminate the inefficiency of the 1D-FGM structures to fullfill the technical requirements such as the temperature and stress distributions in two or three directions for aerospace craft and shuttles and have complex governing equations are very limited in the literature. For instance, the practical engineering applications of the 2D-FGM were presented in [32], by using the Element Free Galerkin Method, 2D steady-state free and forced vibrations of two-directional FG beams are analysed in [33]. The elasticity solutions are proposed for bending and thermal deformations of FGBs with various end conditions by using the state-space based differential quadrature method in [34]. A symplectic elasticity solution for static and free vibration analyses of two-directional FG beams with the material properties varying exponentially in both axial and thickness direction is presented in [35]. The buckling of Timoshenko beams composed of two dimensional FGM was studied in [36]. The dynamic characteristics of the bi-directional functionally graded beams were presented by using the Timoshenko beam formulation in [37]. The static behaviour of two directional FG beams was studied by using a meshless method in [38]. Morever, the studies for the static, dynamic 
and buckling analysis of the FG sandwich structures are also very limited [39-48]. To the best of the author's knowledge, there is no reported work regarding to the static analysis of the two-directional FG sandwich beams based on the different beam theories.

The main scope of this work is to investigate the static behaviour of the two-directional FG sandwich beams based on various beam theories such as Euler Bernoulli Beam Theory (EBT), Timoshenko Beam Theory (TBT) and Reddy Bickford Beam Theory (RBT) by using the Symmetric Smoothed Particle Hydrodynamics (SSPH) method.

In this paper, the elastostatic analysis of the two-directional FG sandwich beams are presented by considering several beam theories, aspect ratios $(\mathrm{L} / \mathrm{h})$, types of sandwich structures and sets of boundary conditions and using power-law distribution.

In section 2, the formulation of the basis function of the SSPH method is given. In section 3, the homogenization of material properties of the 2D-FG sandwich beam is presented. The formulation of the EBT, TBT and RBT based on the studied 2D-FG sandwich beam problems and the SSPH method are given in Section 4. In Section 5, numerical results are given for the problems with four different boundary conditions which are simply supported (SS), clamped- simply supported (CS), clamped-clamped (CC) and clamped-free (CF).

\section{Formulation of symmetric smoothed particle hydrodynamics method}

A scalar function for 1D case can be presented by using Taylor Series Expansion (TSE) as follows

$$
\begin{aligned}
f(\xi) & =f(x)+(\xi-x) f^{\prime}(x)+\frac{1}{2 !}(\xi-x)^{2} f^{\prime \prime}(x)+\frac{1}{3 !}(\xi-x)^{3} f^{\prime \prime \prime}(x) \\
& +\frac{1}{4 !}(\xi-x)^{4} f^{(I V)}(x)+\frac{1}{5 !}(\xi-x)^{5} f^{(V)}(x)+\frac{1}{6 !}(\xi-x)^{6} f^{(V I)}(x)+\text { ldots }
\end{aligned}
$$

where $f(\xi)$ is the value of the function at $\xi$ located in near of $x$. The Eq. (1) can be given by employing the zeroth to sixht order terms and neglecting the higher order terms

$$
f(\xi)=P(\xi, x) Q(x)
$$

where

$$
\begin{aligned}
Q(x) & =\left[f(x), \frac{d f(x)}{d x}, \frac{1}{2 !} \frac{d^{2} f(x)}{d x^{2}}, \frac{1}{6 !} \frac{d^{6} f(x)}{d x^{6}}\right]^{T} \\
P(\xi, x) & =\left[1,(\xi-x),(\xi-x)^{2},(\xi-x)^{6}\right] .
\end{aligned}
$$

The number of terms employed in the TSE can be increased to improve the accuracy depending on the order of the governing equations. However, increasing the number of terms to be employed definitely increases the CPU time and may decrease the effectiveness of the method. Determination of the number of terms mainly depends on the experience of the researcher. To determine the unknown variables given in the $Q(x)$, both sides of Eq. (2) are multiplied with $W(\xi, x) P(\xi, x)^{T}$ and evaluated for every node in the compact support domain (CSD). In the global numbering system, let the particle number of the $j$ th particle in the compact support of $W(\xi, x)$ be $\mathrm{r}(\mathrm{j})$. The following equation is obtained

$$
\sum_{j=1}^{N(x)} f\left(\xi^{r(j)}\right) W\left(\xi^{r(j)}, x\right) P\left(\xi^{r(j)}, x\right)^{T}=\sum_{j=1}^{N(x)}\left[P\left(\xi^{r(j)}, x\right)^{T} W\left(\xi^{r(j)}, x\right) P\left(\xi^{r(j)}, x\right)\right] Q(x)
$$


where $N(x)$ is the number nodes in the (CSD) of the $W(\xi, x)$ as shown in Figure 1. Then, Eq. (5) can be given by

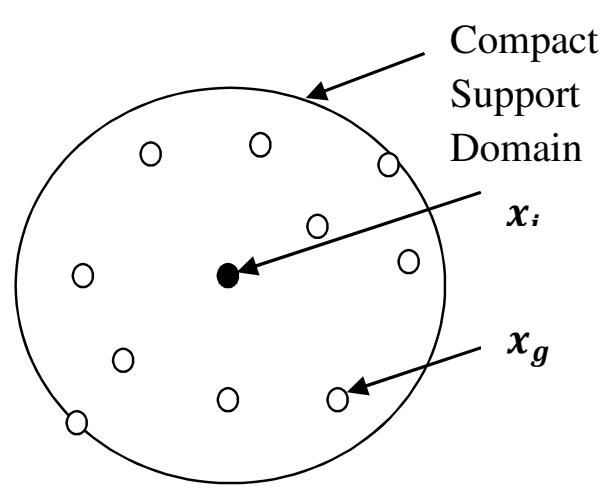

Fig. 1: Compact support of the weight function $W(\xi, x)$ for the node located at $x=\left(x_{i}, y_{i}\right)$.

$$
C(\xi, x) Q(x)=D(\xi, x) F^{(x)}(\xi, x)
$$

where $F^{(x)}(\xi, x)$ are the values of the function $\mathrm{f}$ at all particles located in the compact support of $W(\xi, x)$ associated with point $\mathrm{x}, C(\xi, x)=P(\xi, x)^{T} W(\xi, x) P(\xi, x)$ and $D(\xi, x)=P(\xi, x)^{T} W(\xi, x)$.

The solution of Eq. (6) is given by

$$
Q(x)=K(\xi, x) F(\xi)
$$

where $F(\xi)$ are the values of the function at all particles in the entire domain and $K^{(x)}(\xi, x)=C(\xi, x)^{-1} D(\xi, x)$. Eq. (7) can be also written as follows

$$
Q_{I}(x)=\sum_{J=1}^{M} K_{I J} F_{J}, I=1,2, \ldots, 7
$$

where $\mathrm{M}$ is the number of nodes, $\mathrm{I}$ is the number of terms employed in the TSE and $F_{J}=f\left(\xi^{J}\right)$. Seven components of Eq. (8) for 1D case are written as

$$
\begin{gathered}
f(x)=Q_{1}(x)=\sum_{J=1}^{M} K_{1 J} F_{J} \\
\frac{d f(x)}{d x}=Q_{2}(x)=\sum_{J=1}^{M} K_{2 J} F_{J} \\
\frac{d^{2} f(x)}{d x^{2}}=2 ! Q_{3}(x)=2 ! \sum_{J=1}^{M} K_{3 J} F_{J} \\
\frac{d^{3} f(x)}{d x^{3}}=3 ! Q_{4}(x)=3 ! \sum_{J=1}^{M} K_{4 J} F_{J} \\
\frac{d^{4} f(x)}{d x^{4}}=4 ! Q_{5}(x)=4 ! \sum_{J=1}^{M} K_{5 J} F_{J} \\
\frac{d^{5} f(x)}{d x^{5}}=5 ! Q_{6}(x)=! \sum_{J=1}^{M} K_{6 J} F_{J}
\end{gathered}
$$




$$
\frac{d^{6} f(x)}{d x^{6}}=6 ! Q_{7}(x)=6 ! \sum_{J=1}^{M} K_{7 J} F_{J}
$$

Details of the SSPH method can be found in [49-54].

\section{Homogenization of material properties}

Consider a two-directional functionally graded beam namely Type A as shown in Fig 2a, which is made of a mixture of ceramic and metal, with length $\mathrm{L}$, width $\mathrm{b}$ and thickness $\mathrm{h}$. Two types of FG sandwich beams namely 2D-FG faces metal core (Type B) and 2D-FG faces ceramic core (Type C) are considered.

The rule of mixture is used to find the effective material properties at a point. According to the rule of mixtures, the effective material properties of the beam, Young's modulus E and shear modulus $\mathrm{G}$ can be given by

$$
\begin{gathered}
E(x, z)=E_{1} V_{1}(x, z)+E_{2} V_{2}(x, z) \\
G(x, z)=G_{1} V_{1}(x, z)+G_{2} V_{2}(x, z)
\end{gathered}
$$

where $E_{1}, E_{2}, G_{1}$ and $G_{2}$ are the material properties of two constituents, $V_{1}$ and $V_{2}$ are volume fractions of the constituents. The relation of the volume fractions can be expressed as follows,

$$
V_{1}(x, z)+V_{2}(x, z)=1
$$

\subsection{Type A: $2 D-F G$ beam}

According to the power law form, the volume fraction of the ceramic can be given by

$$
V_{c}(x, z)=\left(1-\frac{x}{2 L}\right)^{p_{x}}\left(\frac{1}{2}+\frac{z}{h}\right)^{p_{z}}
$$

where $p_{x}$ and $p_{z}$ are the gradation exponents (power-law index) which determine the material properties through the thickness and length of the beam, respectively, $\mathrm{L}$ is the length of the beam and $\mathrm{h}$ is the heigth of the beam. When the $p_{x}$ and $p_{z}$ are set to zero the beam becomes homogeneous. The effective material properties can be found by using the Eqs. (10), (11) and (12) as follows

$$
\begin{aligned}
& E(x, z)=\left(E_{c}-E_{m}\right)\left(1-\frac{x}{2 L}\right)^{p_{x}}\left(\frac{1}{2}+\frac{z}{h}\right)^{p_{z}}+E_{m} \\
& G(x, z)=\left(G_{c}-G_{m}\right)\left(1-\frac{x}{2 L}\right)^{p_{x}}\left(\frac{1}{2}+\frac{z}{h}\right)^{p_{z}}+G_{m} .
\end{aligned}
$$




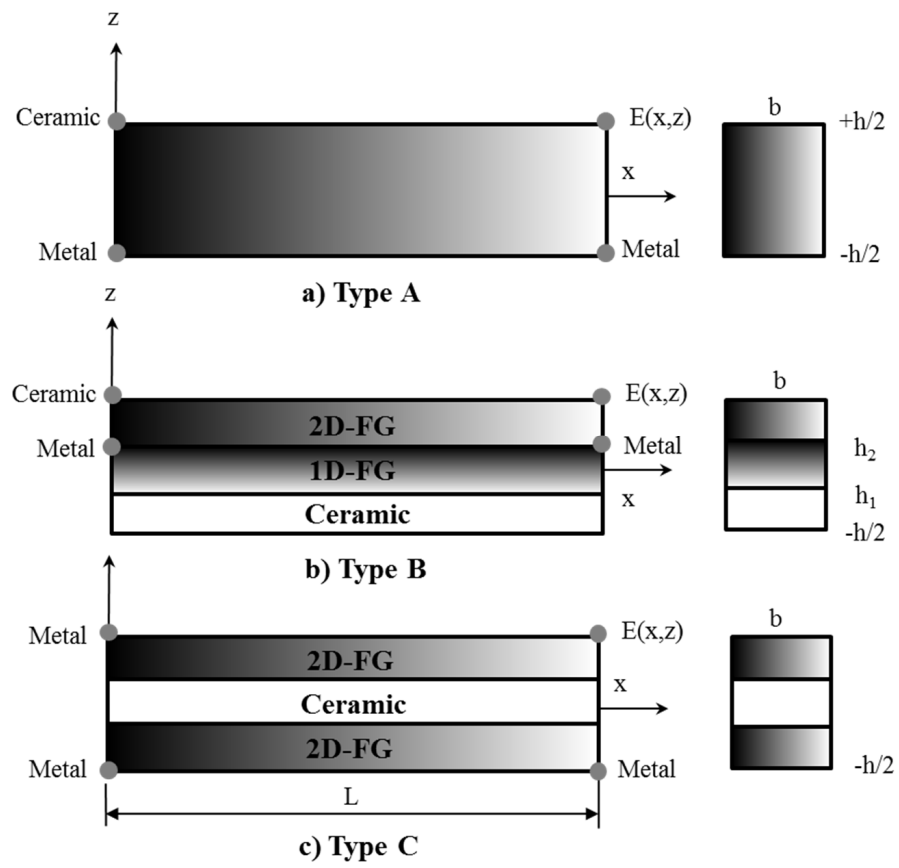

Fig. 2: The variation of elasticity modulus and geometry of a two-directional FG sandwich beam.

\subsection{Type B: sandwich beam with $2 D-F G$ and ceramic faces and $1 D-F G$ core}

The upper face of the sandwich beam is made of 2D-FG, the lower face is made of ceramic and the core is made of $1 \mathrm{D}-\mathrm{FG}$ as shown in Fig. 2b. The volume fraction of the ceramic phase $V_{c}^{(i)}$ given by,

$$
\begin{aligned}
& V_{c}^{(1)}=\left(1-\frac{x}{2 L}\right)^{p_{x}}\left(\frac{2\left(z-h_{2}\right)}{h-2 h_{2}}\right)^{p_{z}} \text { for } z \in\left[h_{2}, h / 2\right] \\
& V_{c}^{(2)}=\left(\frac{z-h_{2}}{h_{1}-h_{2}}\right)^{p_{z}} \text { for } z \in\left[h_{1}, h_{2}\right] \\
& V_{c}^{(3)}=1 \text { for } z \in\left[h_{1},-h / 2\right] .
\end{aligned}
$$

\subsection{Type C: sandwich beam with $2 D-F G$ faces and ceramic core}

The faces of the sandwich beam are made of $2 \mathrm{D}-\mathrm{FG}$ and the core is made of ceramic as shown in Fig. 2b. The volume fraction of the metal phase $V_{m}^{(i)}$ given by,

$$
\begin{aligned}
& V_{m}^{(1)}=\left(1-\frac{x}{2 L}\right)^{p_{x}}\left(\frac{2\left(z-h_{2}\right)}{h-2 h_{2}}\right)^{p_{z}} \text { for } z \in\left[h_{2}, h / 2\right] \\
& V_{m}^{(2)}=0 \text { for } z \in\left[h_{1}, h_{2}\right] \\
& V_{m}^{(3)}=\left(1-\frac{x}{2 L}\right)^{p_{x}}\left(\frac{2\left(h_{1}-z\right)}{h+2 h_{1}}\right)^{p_{z}} \text { for } z \in\left[h_{1},-h / 2\right] .
\end{aligned}
$$




\section{Formulation of beam theories}

The kinematics of deformation of a beam can be represented by using various beam theories. Among them, the Euler Bernoulli Beam Theory (EBT), the Timoshenko Beam Theory (TBT) and the Reddy-Bickford Beam Theory (RBT) are commonly used. The effect of the transverse shear deformation neglected in the EBT is allowed in the latter two beam theories.

To describe the EBT, TBT and RBT, the following coordinate system is introduced. The x-ccordinate is taken along the axis of the beam and the $\mathrm{z}$-coordinate is taken through the height (thickness) of the beam. In the general beam theory, all the loads and the displacements $(\mathrm{u}, \mathrm{w})$ along the coordinates $(\mathrm{x}, \mathrm{z})$ are only the functions of the $\mathrm{x}$ and $\mathrm{z}$ coordinates. The formulation of the beam theories based on the FG sandwich beams and the SSPH formulations are given below.

\subsection{Euler Bernoulli beam theory}

According to EBT, the displacement field is given by,

$$
\begin{aligned}
u(x, z) & =-z \frac{d w_{0}}{d x} \\
w(x, z) & =w_{0}(x)
\end{aligned}
$$

where $\mathrm{w}_{0}$ is the transverse deflection of the beam. The axial strain which is nonzero is given by,

$$
\varepsilon_{x x}=\frac{d u}{d x}=-z \frac{d^{2} w_{0}}{d x^{2}}
$$

The virtual strain energy of the beam can be presented by using the axial stress and the axial strain as follows

$$
\delta U=\int_{0}^{L} \int_{A} \sigma_{x x} \delta \varepsilon_{x x} d A d x
$$

where $\delta$ is the variational operator, $\mathrm{A}$ is the cross sectional area and $\sigma_{x x}$ is the axial stress. The bending moment can be given by,

$$
M_{x x}=\int_{A} z \sigma_{x x} d A
$$

By using Eq. (17) and Eq. (19), Eq. (18) can be rewritten as,

$$
\delta U=-\int_{0}^{L} M_{x x} \frac{d^{2} \delta w_{0}}{d x^{2}} d x
$$

The virtual potential energy of the load $\mathrm{q}(\mathrm{x})$ is given by

$$
\delta V=-\int_{0}^{L} q(x) \delta w_{0} d x
$$

If a body is in equilibrium, $\delta W=\delta U+\delta V$, the total virtual work $(\delta W)$ done equals zero and is given by.

$$
\delta W=-\int_{0}^{L}\left(M_{x x} \frac{d^{2} \delta w_{0}}{d x^{2}}+q(x) \delta w_{0}\right) d x=0 .
$$


After performing integration for the first term in Eq. (22) twice and since $\delta w_{0}$ is arbitrary in $(0<\mathrm{x}<\mathrm{L})$, one can obtain following equilibrium equation

$$
-\frac{d^{2} M_{x x}}{d x^{2}}=q(x) \text { for } 0<x<L .(23)
$$

By introducing the shear force $Q_{x}$ and rewrite the Eq. (23) in the following form

$$
-\frac{d M_{x x}}{d x}+Q_{x}=0,-\frac{d Q_{x}}{d x}=q(x) .
$$

By using Hooke's law, one can obtain

$$
\sigma_{x x}=E(x, z) \varepsilon_{x x}=-E(x, z) z \frac{d^{2} w_{0}}{d x^{2}} .
$$

If the Eq. (25) is put into the Eq. (19), it is obtained,

$$
M_{x x}=-b \int_{-h / 2}^{+h / 2} E(x, z) z^{2} \frac{d^{2} w_{0}}{d x^{2}} d z=-D_{x x} \frac{d^{2} w_{0}}{d x^{2}}
$$

where

$$
D_{x x}=b \int_{-h / 2}^{+h / 2} E(x, z) z^{2} d z .
$$

The EBT governing equation for a FG sandwich beam subjected to the distributed load is given by

$$
\frac{d^{2}}{d x^{2}}\left(D_{x x} \frac{d^{2} w_{0}}{d x^{2}}\right)=q(x) \text { for } 0<x<L .
$$

\subsection{Timoshenko beam theory}

The following displacement field is given for the TBT,

$$
\begin{aligned}
u(x, z) & =z \phi(x) \\
w(x, z) & =w_{0}(x)
\end{aligned}
$$

where $\phi(x)$ is the rotation of the cross section. By using the Eq. (29), the non zero strains can be given by

$$
\begin{aligned}
& \varepsilon_{x x}=\frac{d u}{d x}=z \frac{d \phi}{d x} \\
& \gamma_{x z}=\frac{d u}{d z}+\frac{d w}{d x}=\phi+\frac{d w_{0}}{d x} .
\end{aligned}
$$

The virtual strain energy of the beam including the virtual energy associated with the shearing strain can be written as,

$$
\delta U=\int_{0}^{L} \int_{A}\left(\sigma_{x x} \delta \varepsilon_{x x}+\sigma_{x z} \delta \gamma_{x z}\right) d A d x
$$

where $\sigma_{x z}$ is the transverse shear stress and $\gamma_{x z}$ is the shear strain. The bending moment $M_{x x}$ can be used as given in Eq.(19) and the shear force $Q_{x}$ can be written as following

$$
Q_{x}=\int_{A} \sigma_{x z} d A
$$


By using Eq. (30) and Eq. (32), one can rewrite the Eq.(31) as,

$$
\delta U=\int_{0}^{L}\left[M_{x x} \frac{d \delta \phi}{d x}+Q_{x}\left(\delta \phi+\frac{d \delta w_{0}}{d x}\right)\right] d x
$$

The constituve equations can be written as follows

$$
\begin{aligned}
& \sigma_{x x}=E(x, z) \varepsilon_{x x}=E(x, z) z \frac{d \phi}{d x} \\
& \sigma_{x z}=G(x, z) \gamma_{x z}=G(x, z)\left(\phi+\frac{d w_{0}}{d x}\right) .
\end{aligned}
$$

The bending moment $M_{x x}$ and the shear force $Q_{x}$ can be written in terms of generalized displacement $\left(w_{0}, \phi\right)$ by using Eqs. (34) and (35)

$$
\begin{aligned}
M_{x x} & =b \int_{-h / 2}^{+h / 2} z \sigma_{x x} d z=b \int_{-h / 2}^{+h / 2} E(x, z) z^{2} \frac{d \phi}{d x} d z=D_{x x} \frac{d \phi}{d x} \\
Q_{x} & =\kappa_{s} b \int_{-\frac{h}{2}}^{+\frac{h}{2}} \sigma_{x z} d z=\kappa_{s} b \int_{-\frac{h}{2}}^{+\frac{h}{2}} G(x, z)\left(\phi+\frac{d w_{0}}{d x}\right) d z=\kappa_{s} A_{x z}\left(\phi+\frac{d w_{0}}{d x}\right)
\end{aligned}
$$

where $\kappa_{s}$ is the shear correction factor to be used to compensate the error caused by the assumption of a constant transverse shear stress distribution along the beam thickness and

$$
\begin{aligned}
& D_{x x}=b \int_{-h / 2}^{+h / 2} E(x, z) z^{2} d z \\
& A_{x z}=b \int_{-\frac{h}{2}}^{+\frac{h}{2}} G(x, z) d z .
\end{aligned}
$$

The governing equations of the TBT is given by

$$
\begin{aligned}
& -\frac{d}{d x}\left(D_{x x} \frac{d \phi}{d x}\right)+\kappa_{s} A_{x z}\left(\phi+\frac{d w_{0}}{d x}\right)=0 \\
& -\frac{d}{d x}\left[\kappa_{s} A_{x z}\left(\phi+\frac{d w_{0}}{d x}\right)\right]=q(x) .
\end{aligned}
$$

\subsection{Reddy-Bickford beam theory}

The following displacement field is given for the RBT,

$$
\begin{aligned}
& u(x, z)=z \phi(x)-\alpha z^{3}\left(\phi(x)+\frac{d w(x)}{d x}\right) \\
& w(x, z)=w_{0}(x)
\end{aligned}
$$

where $\alpha=4 /\left(3 h^{2}\right)$. By using the Eq. (40), the strain-displacement relations of the RBT are given by

$$
\begin{aligned}
& \varepsilon_{x x}=\frac{d u}{d x}=z \frac{d \phi}{d x}-\alpha z^{3}\left(\frac{d \phi}{d x}+\frac{d^{2} w_{0}}{d x^{2}}\right) \\
& \gamma_{x z}=\frac{d u}{d z}+\frac{d w}{d x}=\phi+\frac{d w_{0}}{d x}-\beta z^{2}\left(\phi+\frac{d w_{0}}{d x}\right)
\end{aligned}
$$


where $\beta=3 \alpha=4 /\left(h^{2}\right)$. The virtual strain energy of the beam can be written as,

$$
\delta U=\int_{0}^{L} \int_{A}\left(\sigma_{x x} \delta \varepsilon_{x x}+\sigma_{x z} \delta \gamma_{x z}\right) d A d x
$$

and $P_{x x}$ and $R_{x}$ are the higher order stress resultants can be written respectively

$$
\begin{aligned}
& P_{x x}=\int_{A} z^{3} \sigma_{x x} d A, \\
& R_{x}=\int_{A} z^{2} \sigma_{x z} d A .
\end{aligned}
$$

By using Eq. (19), Eq. (32), Eq.(41) and Eq. (43) one can rewrite the Eq.(42) as,

$$
\delta U=\int_{0}^{L}\left[\left(M_{x x}-\alpha P_{x x}\right) \frac{d \delta \phi}{d x}-\alpha P_{x x} \frac{d^{2} \delta w_{0}}{d x^{2}}+\left(Q_{x}-\beta R_{x}\right)\left(\delta \phi+\frac{d \delta w_{0}}{d x}\right)\right] d x .
$$

The constituve equations can be written as follows

$$
\begin{aligned}
& \sigma_{x x}=E(x, z) \varepsilon_{x x}=E(x, z)\left[z \frac{d \phi}{d x}-\alpha z^{3}\left(\frac{d \phi}{d x}+\frac{d^{2} w_{0}}{d x^{2}}\right)\right] \\
& \sigma_{x z}=G(x, z) \gamma_{x z}=G(x, z)\left[\phi+\frac{d w_{0}}{d x}-\beta z^{2}\left(\phi+\frac{d w_{0}}{d x}\right)\right] .
\end{aligned}
$$

The governing equations of the RBT are obtained in terms of displacements $\phi$ and $w_{0}$ as follows,

$$
\begin{aligned}
& -\frac{d}{d x}\left(\bar{D}_{x x} \frac{d \phi}{d x}-\alpha \hat{F}_{x x} \frac{d^{2} w_{0}}{d x^{2}}\right)+\bar{A}_{x z}\left(\phi+\frac{d w_{0}}{d x}\right)=0 \\
& -\alpha \frac{d^{2}}{d x^{2}}\left(\hat{F}_{x x} \frac{d \phi}{d x}-\alpha H_{x x} \frac{d^{2} w_{0}}{d x^{2}}\right)-\frac{d}{d x}\left[\bar{A}_{x z}\left(\phi+\frac{d w_{0}}{d x}\right)\right]=q(x)
\end{aligned}
$$

where

$$
\begin{gathered}
\bar{A}_{x z}=\hat{A}_{x z}-\beta \hat{D}_{x z}, \quad \bar{D}_{x x}=\hat{D}_{x x}-\alpha \hat{F}_{x x}, \\
\hat{D}_{x x}=D_{x x}-\alpha F_{x x}, \quad \hat{F}_{x x}=F_{x x}-\alpha H_{x x}, \\
\hat{A}_{x z}=A_{x z}-\beta D_{x z}, \quad \hat{D}_{x z}=D_{x z}-\beta F_{x z} . \\
\left(D_{x x}, F_{x x}, H_{x x}\right)=b \int_{-h / 2}^{+h / 2} E(x, z)\left(z^{2}, z^{4}, z^{6}\right) d z \\
\left(A_{x z}, D_{x z}, F_{x z}\right)=b \int_{-h / 2}^{+h / 2} G(x, z)\left(1, z^{2}, z^{4}\right) d z .
\end{gathered}
$$

For the type C 2D-FG sandwich beam the followings can be writte

$$
\begin{aligned}
\left(D_{x x}, F_{x x}, H_{x x}\right) & =b\left(\int_{h_{2}}^{+h / 2}\left[\left(E_{m}-E_{c}\right)\left(1-\frac{x}{2 L}\right)^{p_{x}}\left(\frac{2\left(z-h_{2}\right)}{h-2 h_{2}}\right)^{p_{z}}+E_{m}\right]\right. \\
& \left.+\int_{h_{1}}^{h_{2}} E_{c}+\int_{-h / 2}^{h_{1}}\left[\left(E_{m}-E_{c}\right)\left(1-\frac{x}{2 L}\right)^{p_{x}}\left(\frac{2\left(h_{1}-z\right)}{h+2 h_{1}}\right)^{p_{z}}+E_{c}\right]\right)\left(z^{2}, z^{4}, z^{6}\right) d z
\end{aligned}
$$




$$
\begin{aligned}
\left(A_{x z}, D_{x z}, F_{x z}\right) & =b\left(\int_{h_{2}}^{+h / 2}\left[\left(G_{m}-G_{c}\right)\left(1-\frac{x}{2 L}\right)^{p_{x}}\left(\frac{2\left(z-h_{2}\right)}{h-2 h_{2}}\right)^{p_{z}}+G_{c}\right]\right. \\
& \left.+\int_{h_{1}}^{h_{2}} G_{c}+\int_{-h / 2}^{h_{1}}\left[\left(G_{m}-G_{c}\right)\left(1-\frac{x}{2 L}\right)^{p_{x}}\left(\frac{2\left(h_{1}-z\right)}{h+2 h_{1}}\right)^{p_{z}}+G_{c}\right]\right)\left(1, z^{2}, z^{4}\right) d z
\end{aligned}
$$

\subsection{Representation of the governing equations by the SSPH method}

Based on the EBT, the governing equation of the problem can be presented as algebraic equations by using the SSPH basis function given in Eq. (9) and replacing $f(x)$ with $w_{0}(x)$ as follows,

$$
\sum_{j=1}^{M}\left[2 D_{x x, x x} K_{3 J}+12 D_{x x, x} K_{4 J}+24 D_{x x} K_{5 J}\right] W_{J}=q_{0} \text { for } 0<x<L
$$

where

$$
D_{x x, x x}=\frac{d^{2} D_{x x}}{d x^{2}} \text { and } D_{x x, x}=\frac{d D_{x x}}{d x} .
$$

The governing equations of the problem based on the TBT can be written in a similar way by replacing $f(x)$ given in Eq. (9) with $w_{0}(x)$ and $\phi(x)$ and by using the SSPH basis functions as follows,

$$
\sum_{J=1}^{M}\left[\begin{array}{cc}
\kappa_{s} A_{x z} K_{2 J} & \kappa_{s} A_{x z} K_{1 J}-D_{x x, x} K_{2 J}-2 D_{x x} K_{3 J} \\
-\left(\kappa_{s} A_{x z, x} K_{2 J}+2 \kappa_{s} A_{x z} K_{3 J}\right) & -\left(\kappa_{s} A_{x z, x} K_{1 J}+\kappa_{s} A_{x z} K_{2 J}\right)
\end{array}\right]\left[\begin{array}{l}
W_{J} \\
\Phi_{J}
\end{array}\right]=\left[\begin{array}{c}
0 \\
q_{0}
\end{array}\right]
$$

where $A_{x z, x}=\frac{d A_{x z}}{d x}$. The SCF is assumed to be constant as $\kappa_{s}=5 / 6$ for the rectangular cross section. By using RBT and the SSPH basis function the governing equations can be written by replacing $f(x)$ given in Eq. (9) with $w_{0}(x)$ and $\phi(x)$ as follows,

$$
\sum_{J=1}^{M}\left[\begin{array}{cc}
\bar{A}_{x z} K_{2 J}+2 \alpha \hat{F}_{x x, x} K_{3 J}+6 \alpha \hat{F}_{x x} K_{4 J} & \bar{A}_{x z} K_{1 J}-\bar{D}_{x x, x} K_{2 J}-2 \bar{D}_{x x} K_{3 J} \\
\phi_{1} & \phi_{2}
\end{array}\right]\left[\begin{array}{c}
W_{J} \\
\Phi_{J}
\end{array}\right]=\left[\begin{array}{c}
0 \\
q_{0}
\end{array}\right]
$$

where

$$
\begin{gathered}
\phi_{1}=-\bar{A}_{x z, x} K_{2 J}-2 \bar{A}_{x z} K_{3 J}+2 \alpha^{2} H_{x x, x x} K_{3 J}+12 \alpha^{2} H_{x x, x} K_{4 J}+24 \alpha^{2} H_{x x} K_{5 J}, \\
\phi_{2}=-\bar{A}_{x z, x} K_{1 J}-\bar{A}_{x z} K_{2 J}-\alpha \hat{F}_{x x, x x} K_{2 J}-4 \alpha \hat{F}_{x x, x} K_{3 J}-6 \alpha \hat{F}_{x x} K_{4 J}
\end{gathered}
$$

and

$$
\bar{A}_{x z}=\frac{d A_{x z}}{d x}, \hat{F}_{x x, x}=\frac{d \hat{F}_{x x}}{d x}, \hat{F}_{x x, x x}=\frac{d^{2} \hat{F}_{x x}}{d x^{2}}, H_{x x, x}=\frac{d H_{x x}}{d x} \text { and } H_{x x, x x}=\frac{d^{2} H_{x x}}{d x^{2}} .
$$

The boundary conditions which are presented according to the SSPH formulation are given below.

\subsubsection{Simply supported (SS) two-directional FG sandwich beam}

The boundary conditions regarding to the EBT are given as follows,

$$
\begin{aligned}
& x=0, \quad \sum_{J=1}^{M} 2 K_{3 J} W_{J}=0 \text { and } \sum_{J=1}^{M} K_{1 J} W_{J}=0 m \\
& x=L, \quad \sum_{J=1}^{M} 2 K_{3 J} W_{J}=0 \text { and } \sum_{J=1}^{M} K_{1 J} W_{J}=0 \mathrm{~m} .
\end{aligned}
$$


The boundary conditions regarding to the TBT are given as follows,

$$
\begin{aligned}
& x=0, \quad \sum_{J=1}^{M} K_{2 J} \Phi_{J}=0 \text { and } \sum_{J=1}^{M} K_{1 J} W_{J}=0 m \\
& x=L, \quad \sum_{J=1}^{M} K_{2 J} \Phi_{J}=0 \text { and } \sum_{J=1}^{M} K_{1 J} W_{J}=0 m .
\end{aligned}
$$

The boundary conditions regarding to the RBT are given as follows,

$$
\begin{aligned}
& x=0, \quad \sum_{J=1}^{M} \hat{D}_{x x} K_{2 J} \Phi_{J}-\sum_{J=1}^{M} 2 \alpha F_{x x} K_{3 J} W_{J}=0, \text { and } \sum_{J=1}^{M} K_{1 J} W_{J}=0 m \\
& x=L, \quad \sum_{J=1}^{M} \hat{D}_{x x} K_{2 J} \Phi_{J}-\sum_{J=1}^{M} 2 \alpha F_{x x} K_{3 J} W_{J}=0, \text { and } \sum_{J=1}^{M} K_{1 J} W_{J}=0 m .
\end{aligned}
$$

\subsubsection{Clamped simply supported (CS) two-directional FG sandwich beam}

The boundary conditions based on the EBT are given by,

$$
\begin{gathered}
x=0, \quad \sum_{J=1}^{M} K_{2 J} W_{J}=0 \text { and } \sum_{J=1}^{M} K_{1 J} W_{J}=0 m \\
x=L, \quad \sum_{J=1}^{M} 2 K_{3 J} W_{J}=0 \text { and } \sum_{J=1}^{M} K_{1 J} W_{J}=0 m .
\end{gathered}
$$

The boundary conditions based on the TBT are given by,

$$
\begin{aligned}
& x=0, \quad \sum_{J=1}^{M} K_{1 J} \Phi_{J}=0 \text { and } \sum_{J=1}^{M} K_{1 J} W_{J}=0 m \\
& x=L, \quad \sum_{J=1}^{M} K_{2 J} \Phi_{J}=0 \text { and } \sum_{J=1}^{M} K_{1 J} W_{J}=0 \mathrm{~m} .
\end{aligned}
$$

The boundary conditions based on the RBT are given by,

$$
\begin{array}{r}
x=0, \quad \sum_{J=1}^{M} K_{1 J} \Phi_{J}=0 \text { and } \sum_{J=1}^{M} K_{1 J} W_{J}=0 m \\
x=L, \quad \sum_{J=1}^{M} \hat{D}_{x x} K_{2 J} \Phi_{J}-\sum_{J=1}^{M} 2 \alpha F_{x x} K_{3 J} W_{J}=0, \text { and } \sum_{J=1}^{M} K_{1 J} W_{J}=0 m .
\end{array}
$$

\subsubsection{Clamped clamped (CC) two-directional FG sandwich beam}

The boundary conditions based on the EBT are given by,

$$
\begin{aligned}
& x=0, \quad \sum_{J=1}^{M} K_{2 J} W_{J}=0 \text { and } \sum_{J=1}^{M} K_{1 J} W_{J}=0 m \\
& x=L, \quad \sum_{J=1}^{M} K_{2 J} W_{J}=0 \text { and } \sum_{J=1}^{M} K_{1 J} W_{J}=0 m .
\end{aligned}
$$


The boundary conditions based on the TBT are given by,

$$
\begin{aligned}
& x=0, \quad \sum_{J=1}^{M} K_{1 J} \Phi_{J}=0 \text { and } \sum_{J=1}^{M} K_{1 J} W_{J}=0 m \\
& x=L, \quad \sum_{J=1}^{M} K_{1 J} \Phi_{J}=0 \text { and } \sum_{J=1}^{M} K_{1 J} W_{J}=0 m .
\end{aligned}
$$

The boundary conditions based on the RBT are given by,

$$
\begin{aligned}
& x=0, \quad \sum_{J=1}^{M} K_{1 J} \Phi_{J}=0 \text { and } \sum_{J=1}^{M} K_{1 J} W_{J}=0 m \\
& x=L, \quad \sum_{J=1}^{M} K_{1 J} \Phi_{J}=0 \text { and } \sum_{J=1}^{M} K_{1 J} W_{J}=0 m .
\end{aligned}
$$

\subsubsection{Cantilever (CF) two-directional FG sandwich beam}

The boundary conditions based on the EBT are given by,

$$
\begin{array}{r}
x=0, \quad \sum_{J=1}^{M} K_{2 J} W_{J}=0 \text { and } \sum_{J=1}^{M} K_{1 J} W_{J}=0 m \\
x=L, \quad \sum_{J=1}^{M} 2 K_{3 J} W_{J}=0 \text { and } \sum_{J=1}^{M}\left[2 D_{x x, x} K_{3 J}+6 D_{x x} K_{4 J}\right] W_{J}=0 .
\end{array}
$$

The boundary conditions regarding to the TBT are given as follows,

$$
\begin{array}{r}
x=0, \quad \sum_{J=1}^{M} K_{1 J} \Phi_{J}=0 \text { and } \sum_{J=1}^{M} K_{1 J} W_{J}=0 m \\
x=L, \quad \sum_{J=1}^{M} K_{2 J} \Phi_{J}=0 \text { and } \sum_{J=1}^{M} K_{1 J} \Phi_{J}+\sum_{J=1}^{M} K_{2 J} W_{J}=0 .
\end{array}
$$

The boundary conditions regarding to the RBT are given as follows,

$$
\begin{array}{r}
x=0, \quad \sum_{J=1}^{M} K_{1 J} \Phi_{J}=0 \text { and } \sum_{J=1}^{M} K_{1 J} W_{J}=0 m \\
x=L, \quad \sum_{J=1}^{M} \hat{D}_{x x} K_{2 J} \Phi_{J}-\sum_{J=1}^{M} 2 \alpha F_{x x} K_{3 J} W_{J}=0, \text { and } \sum_{J=1}^{M} K_{1 J} \Phi_{J}+\sum_{J=1}^{M} K_{2 J} W_{J}=0 .
\end{array}
$$

\section{Numerical results}

The elastostatic behaviour of the 2D FG sandwich beams are investigated by considering the EBT, TBT and RBT formulations. The numerical results are obtained by using the SSPH method for various gradation exponents, aspect ratios and boundary conditions. As far as author aware, there is no available previous results regarding to the static analysis of 2D FG sandwich beams. At first, the SSPH code is developed based on the 2D FG sandwich beam formulation and then the developed SSPH code is verified by solving a simply supported conventional FG beam problem subjected to uniformly distributed load. The results from previous studies [55] along with the analytical solutions in terms of dimensionless maximum transverse deflections, axial and shear stresses are used for comparison purposes. After the verification of the developed code, the number of nodes to be used in the problem domain for the numerical calculations is determined and extensive analysis are performed.

The physical parameters of the beam are $\mathrm{L}=1 \mathrm{~m}$ and $\mathrm{b}=0.1 \mathrm{~m}$. Two different aspect ratios $(\mathrm{L} / \mathrm{h}) 5$ and 20 are considered. The distributed 
load $q_{0}$ is set to $10000 \mathrm{~N} / \mathrm{m}$. The material properties of the two constitutes are given as

$$
\begin{array}{cc}
\text { Ceramic }\left(\mathrm{Al}_{2} \mathrm{O}_{3}\right) & : E_{c}=380 \mathrm{GPa} \text { and } v_{1}=0.3 \\
\text { Metal (Aluminium) } & : E_{m}=70 \mathrm{GPa} \text { and } v_{2}=0.3
\end{array}
$$

The following non-dimensional quantities are used for the representation of the results.

Non-dimensional maximum transverse deflection of the beam

$$
\begin{aligned}
& \bar{w}=\frac{100 E_{m} b h^{3}}{q_{0} L^{4}} w_{0}\left(\frac{L}{2}, z\right) \text { for } S S, C S \text { and } C C \text { beams } \\
& \bar{w}=\frac{100 E_{m} b h^{3}}{q_{0} L^{4}} w_{0}(L, z) \text { for } C F \text { beams }
\end{aligned}
$$

Non-dimensional axial and shear stresses of the beam:

$$
\begin{gathered}
\bar{\sigma}_{x}=\frac{b h}{q_{0} L} \sigma_{x}\left(\frac{L}{2}, z\right) \\
\bar{\sigma}_{x z}=\frac{b h}{q_{0} L} \sigma_{x z}(0, z) .
\end{gathered}
$$

\subsection{Verification, comparison and convergence studies}

A simply supported FG beam under uniformly distributed load is considered. The SSPH code developed for the Type B sandwich beam is employed for the numerical calculations by setting $p_{x}$ as zero and $h_{1}=h_{2}=-h / 2$. Four types of uniformly node distributions in the problem domain $x \in[0,1]$ for numerical calculations As the weight function, the following Revised Super Gauss Function (RSGF) is employed.

$$
W(x, \xi)=\frac{G}{(h \sqrt{\pi})^{\lambda}}\left\{\begin{array}{cc}
\left(64-d^{2}\right) e^{-d^{2}} & 0 \leq d \leq 8 \\
0 & d>8
\end{array}\right\} \quad d=|x-\xi| / h
$$

where $d$ is the radius of the CSD, his the smoothing length.

The numerical calculations are performed according to the following meshless parameters; the radius of the support domain (d) is chosen as 8 and the smoothing length $(h)$ equals to $1.3 \Delta . \Delta$ can be defined as the minimum distance between two adjacent nodes. The meshless parameters, $d$ and $h$, are selected to obtain the lowest error.

Based on the various node distributions, aspect ratios and gradation exponents, the maximum non-dimensional tranverse deflections, axial and shear stresses are obtained by using different beam theories and given in Table 1-6 along with the results from previous studies and the analytical solution of the problem. It is clear that the results obtained by using the SSPH method agree completely with those of previous paper [55] and the analytical solution. Regarding to numerical results obtained by the EBT and TBT, the transverse deflections, axial and transverse shear stresses are almost the same with the analytical solutions as shown in Table 1-6. And it is also obvious that the results from RBT are in excellent agreement with the results presented in [55]. Due to this agreement, the verification of the developed code is established. For the extensive analysis and the sake of accuracy, uniformly distributed 161 nodes will be used in the problem domain.

\subsection{Elastostatic analysis of two-directional FG sandwich beams}

Four different boundary conditions, SS, CS, CC and CF are considered respectively for the bending analysis of two directional FG sandwich beams subjected to uniformly distributed load. The maximum transverse deflections, axial and shear stresses are computed based on the various beam theories, gradation exponents and aspect ratios. 
Table 1: Verification and convergence studies of the code for S-S FGB, dimensionless maximum transverse deflections for different number of nodes and gradation exponents, $L / h=5$.

\begin{tabular}{|c|c|c|c|c|c|c|}
\hline \multirow[t]{2}{*}{ Theory } & \multirow{2}{*}{$\begin{array}{l}\text { Gradation } \\
\text { Exponent }\left(p_{z}\right)\end{array}$} & \multicolumn{4}{|c|}{ Number of Nodes } & \multirow{2}{*}{$\begin{array}{l}\text { Analytical } \\
\text { Solution } \\
\text { * Li et al [55] }\end{array}$} \\
\hline & & 21 & 41 & 81 & 161 & \\
\hline \multirow{5}{*}{ EBT } & $\overline{0}$ & 2.8783 & 2.8783 & 2.8783 & 2.8783 & 2.8783 \\
\hline & 0.5 & 4.1296 & 4.1296 & 4.1296 & 4.1296 & 4.1296 \\
\hline & 1 & 4.8611 & 4.8611 & 4.8611 & 4.8611 & 4.8611 \\
\hline & 2 & 5.6378 & 5.6378 & 5.6378 & 5.6378 & 5.6378 \\
\hline & 5 & 6.8975 & 6.8975 & 6.8975 & 6.8975 & 6.8975 \\
\hline \multirow{5}{*}{ TBT } & 0 & 3.1657 & 3.1657 & 3.1657 & 3.1657 & 3.1657 \\
\hline & 0.5 & 4.5243 & 4.5243 & 4.5243 & 4.5243 & 4.5243 \\
\hline & 1 & 5.3464 & 5.3464 & 5.3464 & 5.3464 & 5.3464 \\
\hline & 2 & 6.2679 & 6.2679 & 6.2679 & 6.2679 & 6.2679 \\
\hline & 5 & 7.7951 & 7.7951 & 7.7951 & 7.7951 & 7.7951 \\
\hline \multirow{5}{*}{ RBT } & 0 & 3.1657 & 3.1657 & 3.1657 & 3.1658 & $* 3.1657$ \\
\hline & 0.5 & 4.5175 & 4.5175 & 4.5175 & 4.5177 & $* 4.5183$ \\
\hline & 1 & 5.3464 & 5.3464 & 5.3464 & 5.3464 & $* 5.3464$ \\
\hline & 2 & 6.3109 & 6.3109 & 6.3109 & 6.3109 & $* 6.3002$ \\
\hline & 5 & 7.9760 & 7.9759 & 7.9760 & 7.9760 & $* 7.9268$ \\
\hline
\end{tabular}

Table 2: Verification and convergence studies of the code for S-S FGB, dimensionless maximum transverse deflections for different number of nodes and gradation exponents, $L / h=20$.

\begin{tabular}{|c|c|c|c|c|c|c|}
\hline \multirow{3}{*}{ Theory } & \multirow{2}{*}{$\begin{array}{l}\text { Gradation } \\
\text { Exponent }\left(p_{z}\right)\end{array}$} & \multicolumn{4}{|c|}{ Number of Nodes } & $\begin{array}{c}\text { Analytical } \\
\text { Solution }\end{array}$ \\
\cline { 2 - 7 } & & 21 & 41 & 81 & 161 & 2.8783 \\
\hline \hline \multirow{4}{*}{ EBT et al [55] }
\end{tabular}

\subsubsection{SS two-directional FG sandwich beam}

As the first example, simply supported 2D-FG sandwich beam under uniformly distributed load is studied. The maximum dimensionless transverse deflections and stresses are computed from different beam theories for various gradation exponents and aspect ratios. As it is seen form Tables 7-9, the minimum deflection value is obtained from the formulation of EBT is lowest one, as it is expected. The difference between the EBT and the other two theories is significant for thick beam $(\mathrm{L} / \mathrm{h}=5)$, however for thin beam $(\mathrm{L} / \mathrm{h}=20)$, it is negligible.

The computed results in terms of maximum dimensionless transverse deflections by RBT are slightly higher than the results from TBT for type A and type B. With the increasing of the gradation exponents in both directions, the deflection values are increasing. Table 9 shows that the maximum deflection value decreases as the gradation exponent increases in both directions. 
Table 3: Verification and convergence studies of the code for S-S FGB, dimensionless axial stress $\bar{\sigma}_{x}\left(\frac{L}{2}, \frac{h}{2}\right)$ for different number of nodes and gradation exponents, $\mathrm{L} / \mathrm{h}=5$.

\begin{tabular}{|c|c|c|c|c|c|c|}
\hline \multirow{3}{*}{ Theory } & \multirow{2}{*}{$\begin{array}{l}\text { Gradation } \\
\text { Exponent }\left(p_{z}\right)\end{array}$} & \multicolumn{4}{|c|}{ Number of Nodes } & $\begin{array}{c}\text { Analytical } \\
\text { Solution }\end{array}$ \\
\cline { 2 - 7 } & & 21 & 41 & 81 & 161 & Li et al [55] \\
\hline \hline \multirow{4}{*}{ EBT } & 0 & 3.7500 & 3.7500 & 3.7500 & 3.7500 & 3.7500 \\
\cline { 2 - 7 } & 0.5 & 5.3803 & 5.3803 & 5.3803 & 5.3802 & 5.3803 \\
\cline { 2 - 7 } & 1 & 6.3333 & 6.3333 & 6.3333 & 6.3333 & 6.3333 \\
\cline { 2 - 7 } & 2 & 7.3454 & 7.3454 & 7.3454 & 7.3453 & 7.3454 \\
\hline \multirow{4}{*}{ TBT } & 5 & 8.9865 & 8.9865 & 8.9865 & 8.9864 & 8.9865 \\
\cline { 2 - 7 } & 0 & 3.7500 & 3.7500 & 3.7500 & 3.7500 & 3.7500 \\
\cline { 2 - 7 } & 0.5 & 5.3803 & 5.3803 & 5.3803 & 5.3803 & 5.3803 \\
\cline { 2 - 7 } & 1 & 6.3333 & 6.3333 & 6.3333 & 6.3333 & 6.3333 \\
\hline \multirow{4}{*}{ RBT } & 2 & 7.3454 & 7.3454 & 7.3454 & 7.3454 & 7.3454 \\
\cline { 2 - 7 } & 0 & 8.9865 & 8.9865 & 8.9865 & 8.9865 & 8.9865 \\
\cline { 2 - 7 } & 0.5 & 3.8020 & 3.8020 & 3.8020 & 3.8020 & $* 3.8020$ \\
\cline { 2 - 7 } & 1 & 5.4525 & 5.4525 & 5.4525 & 5.4525 & $* 5.4526$ \\
\cline { 2 - 7 } & 2 & 6.4212 & 6.4212 & 6.4212 & 6.4212 & $* 6.4212$ \\
\hline
\end{tabular}

* The values based on analytical solutions from the previous study done by Li et al.

Table 4: Verification and convergence studies of the code for S-S FGB, dimensionless axial stress $\bar{\sigma}_{x}\left(\frac{L}{2}, \frac{h}{2}\right)$ for different number of nodes and gradation exponents, $\mathrm{L} / \mathrm{h}=20$.

\begin{tabular}{|c|c|c|c|c|c|c|}
\hline \multirow{3}{*}{ Theory } & \multirow{2}{*}{$\begin{array}{l}\text { Gradation } \\
\text { Exponent }\left(p_{z}\right)\end{array}$} & \multicolumn{4}{|c|}{ Number of Nodes } & $\begin{array}{c}\text { Analytical } \\
\text { Solution }\end{array}$ \\
\cline { 2 - 7 } & & 21 & 41 & 81 & 161 & Li et al [55] \\
\hline \hline \multirow{4}{*}{ EBT } & 0 & 15.0000 & 15.0000 & 15.0000 & 15.0000 & 15.0000 \\
\cline { 2 - 7 } & 0.5 & 21.5210 & 21.5210 & 21.5211 & 21.5209 & 21.5210 \\
\cline { 2 - 7 } & 1 & 25.3333 & 25.3333 & 25.3334 & 25.3332 & 25.3333 \\
\cline { 2 - 7 } & 2 & 29.3814 & 29.3815 & 29.3815 & 29.3813 & 29.3814 \\
\hline \multirow{4}{*}{ TBT } & 5 & 35.9459 & 35.9460 & 35.9460 & 35.9457 & 35.9459 \\
\cline { 2 - 7 } & 0 & 15.0000 & 15.0000 & 15.0000 & 15.0000 & 15.0000 \\
\cline { 2 - 7 } & 0.5 & 21.5210 & 21.5210 & 21.5211 & 21.5210 & 21.5210 \\
\cline { 2 - 7 } & 1 & 25.3333 & 25.3333 & 25.3334 & 25.3332 & 25.3333 \\
\hline \multirow{5}{*}{ RBT } & 2 & 29.3814 & 29.3815 & 29.3815 & 29.3813 & 29.3814 \\
\cline { 2 - 7 } & 0 & 35.9459 & 35.9460 & 35.9460 & 35.9460 & 35.9459 \\
\cline { 2 - 7 } & 0.5 & 15.0130 & 15.0130 & 15.0130 & 15.0130 & $* 15.0130$ \\
\cline { 2 - 7 } & 1 & 21.5391 & 21.5391 & 21.5391 & 21.5391 & $* 21.5391$ \\
\cline { 2 - 7 } & 2 & 25.3553 & 25.3553 & 25.3553 & 25.3553 & $* 25.3553$ \\
\hline
\end{tabular}

* The values based on analytical solutions from the previous study done by Li et al.

In figs. 3-6, the axial and shear stresses for various theories and gradation exponents in $\mathrm{z}$ and $\mathrm{x}$ directions are plotted, the aspect ratio is set to $\mathrm{L} / \mathrm{h}=5$. It is found that the axial stresses computed based on the EBT and TBT formulation are almost same. However, the results obtained based on the RBT formulation is slightly higher than the others as it is found for the problem studied for the verification of the code. Based on the calculations of sandwich beam Type A, it is clear that the maximum shear stress increases by increasing of gradation exponent in $\mathrm{z}$ direction whereas the maximum axial stress decreases for TBT by increasing of gradation exponent in $\mathrm{x}$ direction. However, the same results are not obtained for RBT. When the gradation exponent $\mathrm{p}_{z}$ is set to 5, the maximum shear stress is lower than the stress obtained for the one obtained by $\mathrm{p}_{z}=2$. As it is expected, the shear stress is zero at the top and the bottom surface of the beam for RBT. It is clear that the maximum dimensionless axial stress increases as the gradation exponent in $\mathrm{x}$ direction increases. The maximum dimensionless shear stress increases with the increasing of the gradation exponent in $\mathrm{z}$ direction as it is presented in Fig. 
Table 5: Verification and convergence studies of the code for S-S FGB, dimensionless transverse shear stress $\bar{\sigma}_{x z}(0,0)$ for different number of nodes and gradation exponents, $L / h=5$.

\begin{tabular}{|c|c|c|c|c|c|c|}
\hline \multirow{3}{*}{ Theory } & \multirow{2}{*}{$\begin{array}{l}\text { Gradation } \\
\text { Exponent }\left(p_{z}\right)\end{array}$} & \multicolumn{4}{|c|}{ Number of Nodes } & $\begin{array}{c}\text { Analytical } \\
\text { Solution } \\
\text { Li et al [55] }\end{array}$ \\
\cline { 2 - 7 } & & 21 & 41 & 81 & 161 & 0.6000 \\
\hline \hline \multirow{3}{*}{ TBT } & 0 & 0.6000 & 0.6000 & 0.6000 & 0.6000 & 0.6272 \\
\cline { 2 - 7 } & 0.5 & 0.6272 & 0.6272 & 0.6272 & 0.6272 & 0.6000 \\
\cline { 2 - 7 } & 1 & 0.6000 & 0.6000 & 0.6000 & 0.6000 & 0.5106 \\
\cline { 2 - 7 } & 2 & 0.5106 & 0.5106 & 0.5106 & 0.5106 & 0.3930 \\
\hline \multirow{3}{*}{ RBT } & 5 & 0.3930 & 0.3930 & 0.3930 & 0.3930 & $* 0.7500$ \\
\cline { 2 - 7 } & 0 & 0.7500 & 0.7500 & 0.7500 & 0.7500 & $* 0.7676$ \\
\cline { 2 - 7 } & 0.5 & 0.7662 & 0.7662 & 0.7662 & 0.7662 & $* 0.7500$ \\
\cline { 2 - 7 } & 1 & 0.7500 & 0.7500 & 0.7500 & 0.7500 & $* 0.6787$ \\
\cline { 2 - 7 } & 2 & 0.6897 & 0.6897 & 0.6897 & 0.6897 & $* 0.67$ \\
\hline
\end{tabular}

* The values based on analytical solutions from the previous study done by Li et al.

Table 6: Verification and convergence studies of the code for S-S FGB, dimensionless transverse shear stress $\bar{\sigma}_{x z}(0,0)$ for different number of nodes and gradation exponents, $L / h=20$.

\begin{tabular}{|c|c|c|c|c|c|c|}
\hline \multirow{2}{*}{ Theory } & \multirow{2}{*}{$\begin{array}{l}\text { Gradation } \\
\text { Exponent }\left(p_{z}\right)\end{array}$} & \multicolumn{4}{|c|}{ Number of Nodes } & \multirow{2}{*}{$\begin{array}{l}\text { Analytical } \\
\text { Solution } \\
* \text { Li et al [55] }\end{array}$} \\
\hline & & 21 & 41 & 81 & 161 & \\
\hline \multirow{5}{*}{ TBT } & 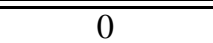 & 0.6000 & 0.6000 & 0.6000 & 0.6000 & 0.6000 \\
\hline & 1 & 0.6272 & 0.6272 & 0.6272 & 0.6272 & 0.6272 \\
\hline & 2 & 0.6000 & 0.6000 & 0.6000 & 0.6000 & 0.6000 \\
\hline & 5 & 0.5106 & 0.5106 & 0.5106 & 0.5106 & 0.5106 \\
\hline & 10 & 0.3930 & 0.3930 & 0.3930 & 0.3930 & 0.3930 \\
\hline \multirow{5}{*}{ RBT } & 0 & 0.7500 & 0.7500 & 0.7500 & 0.7500 & $* 0.7500$ \\
\hline & 1 & 0.7662 & 0.7662 & 0.7662 & 0.7662 & $* 0.7676$ \\
\hline & 2 & 0.7500 & 0.7500 & 0.7500 & 0.7500 & $* 0.7500$ \\
\hline & 5 & 0.6897 & 0.6897 & 0.6897 & 0.6897 & $* 0.6787$ \\
\hline & 10 & 0.6067 & 0.6067 & 0.6067 & 0.6067 & $* 0.5790$ \\
\hline
\end{tabular}

*The values based on analytical solutions from the previous study done by Li et al.

6 for Type B. Regarding to the calculations performed for type C, it is found that the shear stress increases as the gradation exponent in $\mathrm{z}$ direction increases. As it is seen from Fig. 6c, the jumps occur for both TBT and RBT because of the material discontinuity.

\subsubsection{CS two-directional FG sandwich beam}

In this example, the static behavior of a clamped-simply supported two directional FG sandwich beam under uniformly distributed load is considered. The results are given in Tables 10-12 and Figs. 7-10 for different beam theories, gradation exponents and aspect ratios. It is clear from Tables 10-12 that, the EBT underestimates the transverse deflections for a thick beam, as expected it acts more stiff than the other two beam models. However, for a thin beam $(\mathrm{L} / \mathrm{h}=20)$, the difference is negligible. The computed results by RBT are again slightly higher than the results from TBT in type A and type B. As the gradation exponents in both directions increase, the transverse deflections increase for type A and type B. However, for type $\mathrm{C}$, as the gradation exponent increases the transverse deflection decreases. It is found that the lowest maximum dimensionless axial stress value is obtained by the EBT formulation. However, the results obtained based on the RBT formulation are slightly higher than the other two beam theories. The computed numerical results for sandwich beam Type A show that the maximum dimensionless axial stress is obtained when the $\mathrm{p}_{z}$ is set to 0 . The shear stress increases by increasing of gradation exponent in $\mathrm{z}$ direction whereas the maximum axial stress decreases for TBT by increasing of gradation exponent in $\mathrm{x}$ direction. For RBT, the maximum shear stress is obtained when the $\mathrm{p}_{z}$ is set to 2. As gradation exponent in $\mathrm{z}$ direction increase the maximum axial stress increases for type B as shown in Fig. 8. Regarding to the calculations performed for type B, the shear stress 
Table 7: Dimensionless maximum transverse deflections of the FG sandwich S-S beams for different beam theories and gradation exponents, Type A.

\begin{tabular}{|c|c|c|c|c|c|c|c|c|c|c|c|}
\hline \multirow{3}{*}{ Theory } & \multirow{3}{*}{$P_{z}$} & \multicolumn{5}{|c|}{$\mathrm{L} / \mathrm{h}=5$} & \multicolumn{5}{|c|}{$\mathrm{L} / \mathrm{h}=20$} \\
\hline & & \multicolumn{5}{|c|}{$p_{x}$} & \multicolumn{5}{|c|}{$p_{x}$} \\
\hline & & 0 & 0.5 & 1 & 2 & 5 & 0 & 0.5 & 1 & 2 & 5 \\
\hline \multirow{5}{*}{ EBT } & 0 & 2.8783 & 3.2437 & 3.6487 & 4.5720 & 7.8224 & 2.8783 & 3.2437 & 3.6487 & 4.5720 & 7.8224 \\
\hline & 0.5 & 4.1296 & 4.5955 & 5.0960 & 6.1772 & 9.4607 & 4.1296 & 4.5955 & 5.0960 & 6.1772 & 9.4607 \\
\hline & 1 & 4.8611 & 5.3703 & 5.977 & 7.0356 & 10.2286 & 4.8611 & 5.3703 & 5.977 & 7.0356 & 10.2286 \\
\hline & 2 & 5.6378 & 6.1810 & 6.7436 & 7.8916 & 10.9342 & 5.6378 & 6.1810 & 6.7436 & 7.8916 & 10.9342 \\
\hline & 5 & 6.8975 & 7.4699 & 8.0458 & 9.1719 & 11.8976 & 6.8975 & 7.4699 & 8.0458 & 9.1719 & 11.8976 \\
\hline \multirow{5}{*}{ TBT } & 0 & 3.1657 & 3.5714 & 4.0238 & 5.0595 & 8.6549 & 2.8962 & 3.2642 & 3.6721 & 4.6024 & 7.8742 \\
\hline & 0.5 & 4.5243 & 5.0400 & 5.5961 & 6.8004 & 10.3999 & 4.1543 & 4.6232 & 5.1272 & 6.2161 & 9.5193 \\
\hline & 1 & 5.3464 & 5.9113 & 6.5087 & 7.7623 & 11.2435 & 4.8915 & 5.4041 & 5.9452 & 7.0809 & 10.2919 \\
\hline & 2 & 6.2679 & 6.8719 & 7.4972 & 8.7657 & 12.0524 & 5.6773 & 6.2241 & 6.7907 & 7.9462 & 11.0038 \\
\hline & 5 & 7.7951 & 8.4266 & 9.0584 & 10.2806 & $13.170 \varnothing$ & 6.9536 & 7.5296 & 8.1090 & 9.2412 & 11.9770 \\
\hline \multirow{5}{*}{ RBT } & 0 & 3.1658 & 3.5714 & 4.0237 & 5.0596 & 8.6546 & 2.8962 & 3.2641 & 3.6721 & 4.6023 & 7.8742 \\
\hline & 0.5 & 4.5177 & 5.0327 & 5.5887 & 6.7924 & 10.3939 & 4.1538 & 4.6228 & 5.1267 & 6.2156 & 9.5189 \\
\hline & 1 & 5.3464 & 5.9110 & 6.5085 & 7.7623 & 11.2433 & 4.8914 & 5.4041 & 5.9452 & 7.0808 & 10.2918 \\
\hline & 2 & 6.3111 & 6.9154 & 7.5397 & 8.8052 & 12.0793 & 5.6799 & 6.2268 & 6.7933 & 7.9486 & 11.0055 \\
\hline & 5 & 7.9761 & 8.5963 & 9.2143 & 10.4114 & 13.2574 & 6.9649 & 7.5402 & 8.1187 & 9.2493 & 11.9824 \\
\hline
\end{tabular}

Table 8: Dimensionless maximum transverse deflections of the FG sandwich S-S beams for different beam theories and gradation exponents, Type B.

\begin{tabular}{|c|c|c|c|c|c|c|c|c|c|c|c|}
\hline \multirow{3}{*}{ Theory } & \multirow{3}{*}{$P_{z}$} & \multicolumn{5}{|c|}{$\mathrm{L} / \mathrm{h}=5$} & \multicolumn{5}{|c|}{$\mathrm{L} / \mathrm{h}=20$} \\
\hline & & \multicolumn{5}{|c|}{$p_{x}$} & \multicolumn{5}{|c|}{$p_{x}$} \\
\hline & & 0 & 0.5 & 1 & 2 & 5 & 0 & 0.5 & 1 & 2 & 5 \\
\hline \multirow{5}{*}{ EBT } & 0 & 2.8783 & 3.0256 & 3.1644 & 3.4115 & 3.9155 & 2.8783 & 3.0256 & 3.1644 & 3.4115 & 3.9155 \\
\hline & 0.5 & 3.2960 & 3.4399 & 3.5733 & 3.8062 & 4.2649 & 3.2960 & 3.4399 & 3.5733 & 3.8062 & 4.2649 \\
\hline & 1 & 3.5587 & 3.6934 & 3.8168 & 4.0291 & 4.4368 & 3.5587 & 3.6934 & 3.8168 & 4.0291 & 4.4368 \\
\hline & 2 & 3.8897 & 4.0061 & 4.1108 & 4.2876 & 4.6163 & 3.8897 & 4.0061 & 4.1108 & 4.2876 & 4.6163 \\
\hline & 5 & 4.3705 & 4.4515 & 4.5227 & 4.6395 & 4.8477 & 4.3705 & 4.4515 & 4.5227 & 4.6395 & 4.8477 \\
\hline \multirow{5}{*}{ TBT } & 0 & 3.1657 & 3.3216 & 3.4677 & 3.7261 & 4.2473 & 2.8962 & 3.0441 & 3.1834 & 3.4312 & 3.9363 \\
\hline & 0.5 & 3.6570 & 3.8098 & 3.9509 & 4.1952 & 4.6710 & 3.3186 & 3.4630 & 3.5969 & 3.8306 & 4.2903 \\
\hline & 1 & 3.9727 & 4.1163 & 4.2470 & 4.4704 & 4.8943 & 3.5846 & 3.7199 & 3.8437 & 4.0567 & 4.4654 \\
\hline & 2 & 4.3751 & 4.4995 & 4.6107 & 4.7974 & 5.1403 & 3.9201 & 4.0370 & 4.1420 & 4.3195 & 4.6491 \\
\hline & 5 & 4.9568 & 5.0437 & 5.1195 & 5.2431 & 5.4610 & 4.4072 & 4.4886 & 4.5601 & 4.6773 & 4.8860 \\
\hline \multirow{5}{*}{ RBT } & 0 & 3.1658 & 3.3172 & 3.4597 & 3.7126 & 4.2256 & 2.8962 & 3.0438 & 3.1829 & 3.4303 & 3.9349 \\
\hline & 0.5 & 3.6722 & 3.8205 & 3.9573 & 4.1959 & 4.6640 & 3.3195 & 3.4637 & 3.5973 & 3.8306 & 4.2898 \\
\hline & 1 & 4.0095 & 4.1483 & 4.2750 & 4.4930 & 4.9097 & 3.5869 & 3.7218 & 3.8454 & 4.0581 & 4.4664 \\
\hline & 2 & 4.4556 & 4.5754 & 4.6834 & 4.8657 & 5.2039 & 3.9251 & 4.0417 & 4.1466 & 4.3228 & 4.6531 \\
\hline & 5 & 5.1232 & 5.2073 & 5.2815 & 5.4033 & 5.6191 & 4.4175 & 4.4988 & 4.5702 & 4.6872 & 4.8959 \\
\hline
\end{tabular}

increases as the gradation exponent increases in $\mathrm{z}$ direction as plotted in Fig. 10b. Again, the jumps occur for both TBT and RBT because of the material discontinuity in Fig. 10c.

\subsubsection{CC two-directional FG sandwich beam}

The dimensionless maximum transverse deflections and the axial and shear stresses of the clamped-clamped FG sandwich beams are investigated in the third example. The computed results are given in Tables 13-15 and Figs. 11-14. It is clear in that the transverse deflections increase as the power low index increases for Type A and Type B. The difference between the EBT and the other two theories is significant for thick beam $(\mathrm{L} / \mathrm{h}=5)$, however it is negligible for thin beam $(\mathrm{L} / \mathrm{h}=20)$. 
Table 9: Dimensionless maximum transverse deflections of the FG sandwich S-S beams for different beam theories and gradation exponents, Type $\mathrm{C}$.

\begin{tabular}{|c|c|c|c|c|c|c|c|c|c|c|c|}
\hline \multirow{3}{*}{ Theory } & \multirow{3}{*}{$P_{z}$} & \multicolumn{5}{|c|}{$\mathrm{L} / \mathrm{h}=5$} & \multicolumn{5}{|c|}{$\mathrm{L} / \mathrm{h}=20$} \\
\hline & & \multicolumn{5}{|c|}{$p_{x}$} & \multicolumn{5}{|c|}{$p_{x}$} \\
\hline & & 0 & 0.5 & 1 & 2 & 5 & 0 & 0.5 & 1 & 2 & 5 \\
\hline \multirow{5}{*}{ EBT } & 0 & 10.0574 & 7.5933 & 6.3254 & 5.0051 & 3.6549 & 10.0574 & 7.5933 & 6.3254 & 5.0051 & 3.6549 \\
\hline & 0.5 & 6.2044 & 5.3800 & 4.8472 & 4.1951 & 3.4037 & 6.2044 & 5.3800 & 4.8472 & 4.1951 & 3.4037 \\
\hline & 1 & 5.0798 & 4.6093 & 4.2793 & 3.8479 & 3.2815 & 5.0798 & 4.6093 & 4.2793 & 3.8479 & 3.2815 \\
\hline & 2 & 4.2087 & 3.9628 & 3.7783 & 3.5211 & 3.1566 & 4.2087 & 3.9628 & 3.7783 & 3.5211 & 3.1566 \\
\hline & 5 & 3.4957 & 3.3974 & 3.3188 & 3.2028 & 3.0249 & 3.4957 & 3.3974 & 3.3188 & 3.2028 & 3.0249 \\
\hline \multirow{5}{*}{ TBT } & 0 & 10.5428 & 8.0382 & 6.7451 & 5.3942 & 4.0056 & 10.0878 & 7.6211 & 6.3517 & 5.0294 & 3.6769 \\
\hline & 0.5 & 6.5991 & 5.7557 & 5.2098 & 4.5410 & 3.7278 & 6.2291 & 5.4035 & 4.8699 & 4.2168 & 3.4240 \\
\hline & 1 & 5.4408 & 4.9581 & 4.6193 & 4.1764 & 3.5947 & 5.1024 & 4.6311 & 4.3006 & 3.8684 & 3.3011 \\
\hline & 2 & 4.5413 & 4.2883 & 4.0986 & 3.8343 & 3.4603 & 4.2295 & 3.9832 & 3.7983 & 3.5407 & 3.1756 \\
\hline & 5 & 3.8041 & 3.7027 & 3.6217 & 3.5024 & 3.3200 & 3.5150 & 3.4165 & 3.3378 & 3.2216 & 3.0433 \\
\hline \multirow{5}{*}{ RBT } & 0 & 10.451 & 7.9600 & 6.6767 & 5.3384 & 3.9678 & 10.0821 & 7.6162 & 6.3473 & 5.0259 & 3.6745 \\
\hline & 0.5 & 6.5551 & 5.7167 & 5.1746 & 4.5113 & 3.7058 & 6.2293 & 5.4011 & 4.8677 & 4.2149 & 3.4226 \\
\hline & 1 & 5.4127 & 4.9329 & 4.5967 & 4.1567 & 3.5795 & 5.1006 & 4.6295 & 4.2991 & 3.8672 & 3.3001 \\
\hline & 2 & 4.5259 & 4.2748 & 4.0861 & 3.8232 & 3.4508 & 4.2286 & 3.9823 & 3.7975 & 3.5400 & 3.1750 \\
\hline & 5 & 3.7991 & 3.6980 & 3.6173 & 3.4983 & 3.3161 & 10.0574 & 7.5933 & 6.3254 & 5.0051 & 3.6549 \\
\hline
\end{tabular}

Table 10: Dimensionless maximum transverse deflections of the FG sandwich C-S beams for different beam theories and gradation exponents, Type A.

\begin{tabular}{|c|c|c|c|c|c|c|c|c|c|c|c|}
\hline \multirow{3}{*}{ Theory } & \multirow{3}{*}{$P_{z}$} & \multicolumn{5}{|c|}{$\mathrm{L} / \mathrm{h}=5$} & \multicolumn{5}{|c|}{$\mathrm{L} / \mathrm{h}=20$} \\
\hline & & \multicolumn{5}{|c|}{$p_{x}$} & \multicolumn{5}{|c|}{$p_{x}$} \\
\hline & & 0 & 0.5 & 1 & 2 & 5 & 0 & 0.5 & 1 & 2 & 5 \\
\hline \multirow{5}{*}{ EBT } & $\overline{\overline{0}}$ & 1.1972 & $\bar{~} 1.3301$ & 1.4733 & 1.7845 & 2.7279 & 1.1972 & 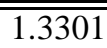 & 1.4733 & 1.7845 & 2.7279 \\
\hline & 0.5 & 1.7176 & 1.8872 & 2.0643 & 2.4296 & 3.3975 & 1.7176 & 1.8872 & 2.0643 & 2.4296 & 3.3975 \\
\hline & 1 & 2.0219 & 2.2072 & 2.3975 & 2.7791 & 3.7281 & 2.0219 & 2.2072 & 2.3975 & 2.7791 & 3.7281 \\
\hline & 2 & 2.3450 & 2.5426 & 2.7419 & 3.1311 & 4.0432 & 2.3450 & 2.5426 & 2.7419 & 3.1311 & 4.0432 \\
\hline & 5 & 2.8689 & 3.0772 & 3.2817 & 3.6642 & 4.4918 & 2.8689 & 3.0772 & 3.2817 & 3.6642 & 4.4918 \\
\hline \multirow{5}{*}{ TBT } & 0 & 1.5275 & 1.6915 & 1.8695 & 2.2591 & 3.4454 & 1.2178 & 1.3527 & 1.4981 & 1.8142 & 2.7728 \\
\hline & 0.5 & 2.1713 & 2.3794 & 2.5980 & 3.0524 & 4.2647 & 1.7460 & 1.9179 & 2.0977 & 2.4686 & 3.4518 \\
\hline & 1 & 2.5797 & 2.8082 & 3.0440 & 3.5191 & 4.7064 & 2.0568 & 2.2447 & 2.4376 & 2.8254 & 3.7894 \\
\hline & 2 & 3.0691 & 3.3145 & 3.5624 & 4.0457 & 5.1784 & 2.3903 & 2.5908 & 2.7932 & 3.1883 & 4.1142 \\
\hline & 5 & 3.9005 & 4.1567 & 4.4065 & 4.8710 & 5.8706 & 2.9334 & 3.1448 & 3.3520 & 3.7398 & 4.5779 \\
\hline \multirow{5}{*}{ RBT } & 0 & 1.5883 & 1.7549 & 1.9357 & 2.3312 & 3.5308 & 1.2217 & 1.3568 & 1.5023 & 1.8187 & 2.7782 \\
\hline & 0.5 & 2.2436 & 2.4542 & 2.6758 & 3.1360 & 4.3615 & 1.7506 & 1.9227 & 2.1026 & 2.4739 & 3.4580 \\
\hline & 1 & 2.6823 & 2.9146 & 3.1540 & 3.6363 & 4.8378 & 2.0634 & 2.2515 & 2.4449 & 2.8329 & 3.7978 \\
\hline & 2 & 3.2683 & 3.5193 & 3.7722 & 4.2632 & 5.4062 & 2.4030 & 2.6039 & 2.8066 & 3.2021 & 4.1287 \\
\hline & 5 & 4.3637 & 4.6197 & 4.8680 & 5.3283 & 6.3107 & 2.9631 & 3.1744 & 3.3815 & 3.7689 & 4.6059 \\
\hline
\end{tabular}

In Figs. 11-14, the axial and shear stresses for various theories and gradation exponents in $\mathrm{z}$ and directions are given for a clampedclamped FG sandwich beam where the aspect ratio is set to $\mathrm{L} / \mathrm{h}=5$. The computed axial stresses for the EBT and TBT formulation are almost same. However, the results based on the RBT formulation are slightly higher than the two beam theories. Based on the calculations of sandwich beam Type $\mathrm{A}$, it is clear that the maximum axial stress increases by decreasing of gradation exponent in $\mathrm{x}$ direction whereas the maximum shear stress decreases for TBT by increasing of gradation exponent in $\mathrm{z}$ direction. It is interesting that the maximum shear stress value is obtained by the RBT formulation when the $p_{z}$ is set to 2 . As it is expected, the shear stress is zero at the top and the bottom surface of the beam for RBT for all types of sandwich beams. For type B, the axial stress increase as the gradation exponent increase in $\mathrm{x}$ direction as plotted in Fig. 12. Because of the symmetry in Type $\mathrm{C}$, the axial and shear stress values are symmetrical according to the midplane of the beam. The maximum dimensionless shear stress is obtained for RBT beam as it is 

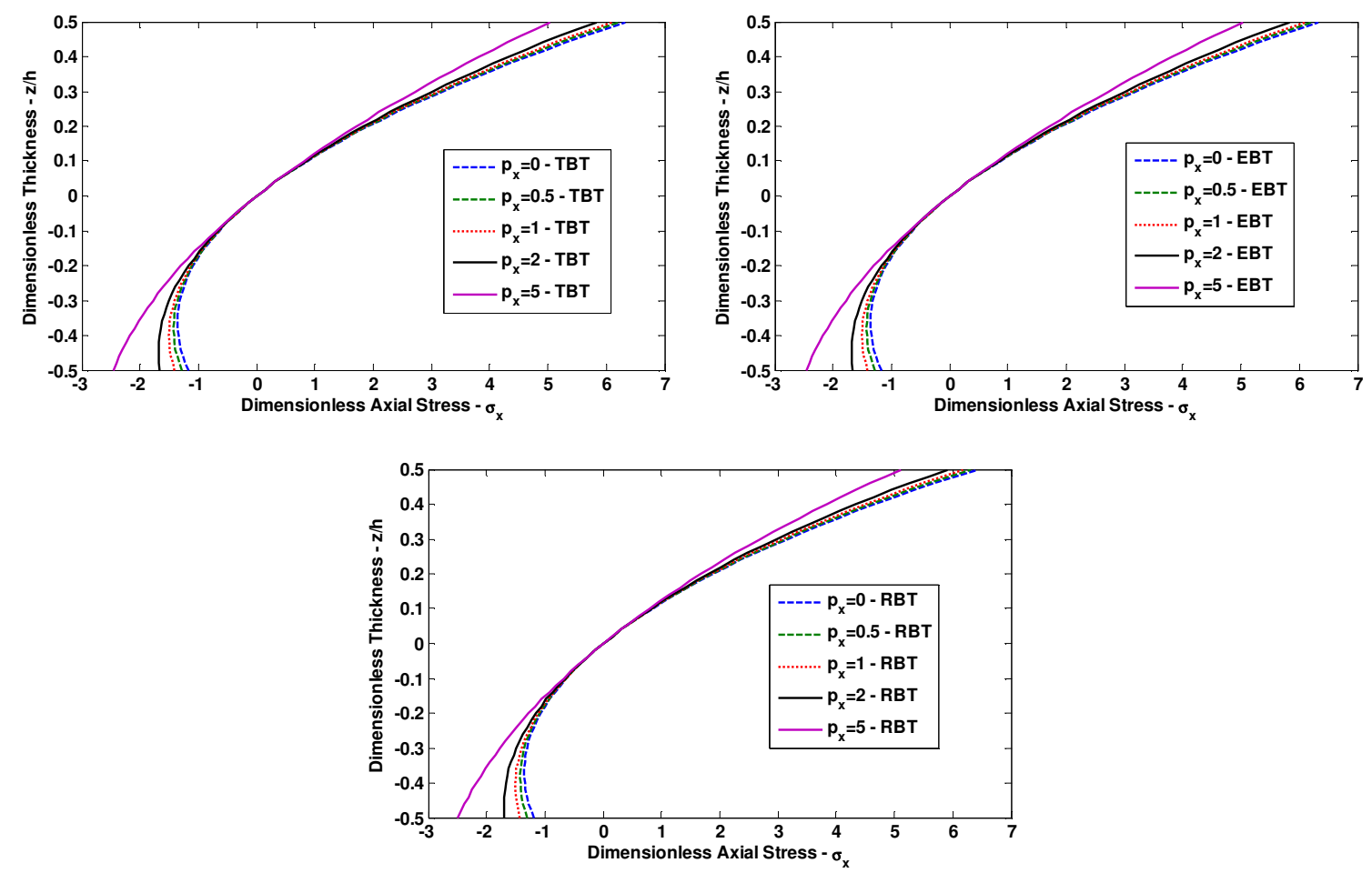

Fig. 3: Dimensionless axial stress $\bar{\sigma}_{x}\left(\frac{L}{2}, z\right)$ through the thickness of the FG sandwich S-S beams for different beam theories and $\mathrm{p}_{z}=1, \mathrm{~L} / \mathrm{h}=5$, Type A.

presented in Fig. 14b for Type B. Computed results show that in Fig. 14c, the shear stress increases as the gradation exponent in $\mathrm{z}$ direction increases. The jumps are still available based on the material discontinuity.

\subsubsection{CF two-directional FG sandwich beam}

Finally, the results of elastostatic anaylsis of the clamped free 2D-FG sandwich beam under uniformly distributed load are given in this example for varios beam theories, gradation exponents and aspect ratios. As it is seen from Tables 16-17, the transverse deflections increase as the gradation exponent increases. The results presented in Table 18 show that the deflections decreases by increasing of the gradation exponent for both directions. Due to the higher stiffness, the dimensionless maximum taransverse deflections values computed based on the EBT are smaller than the ones obtained by TBT and RBT for the aspect ratio set to 5. However, the computed results are very close to each other when the aspect ratio is set to 20 . To obtain more accurate results for the EBT, the smoothing length $(h)$ is set to $1.5 \Delta$ for the problem studied here. The dimensionless axial stress increases as the gradation exponent in $\mathrm{x}$ direction increases for type A and type B as shown in figs. 15-16. And also it is clear that the difference in terms of maximum dimensionless axial stress value is almost negligible for all beam theories as plotted in figs 15-17. Based on the numerical results obtained for Type A, the maximum shear stress is obtained for TBT as presented in fig. 18a. The material changings are visible through the thickness as shown in Fig 18b. The maximum shear stress values are obtained for the maximum gradation exponent in $\mathrm{z}$ direction. As it is seen in fig. 18c, the shear stress value increases with the decreasing of the gradation exponent in $\mathrm{z}$ direction. 

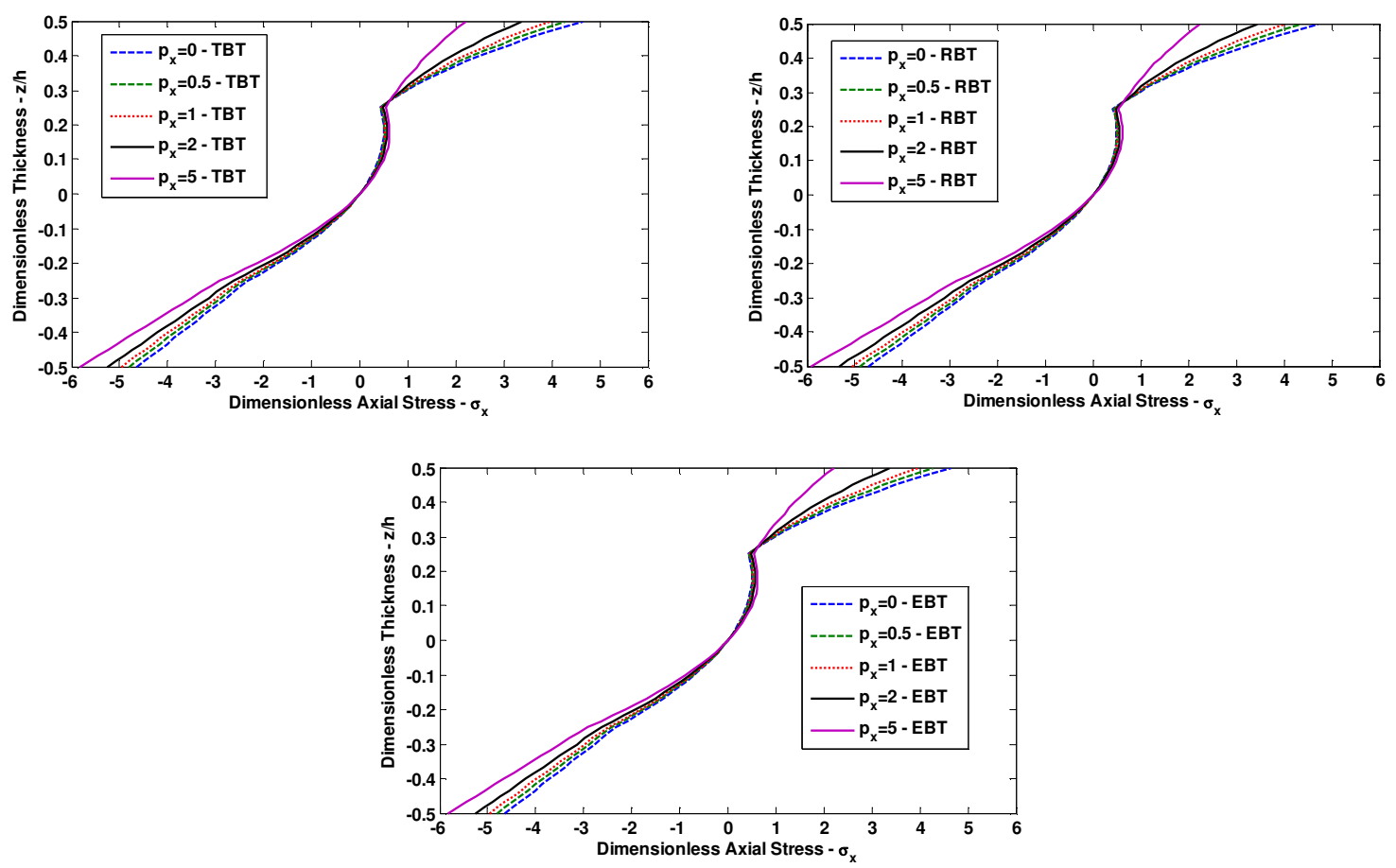

Fig. 4: Dimensionless axial stress $\bar{\sigma}_{x}\left(\frac{L}{2}, z\right)$ through the thickness of the FG sandwich S-S beams for different beam theories and $\mathrm{p}_{z}=1, \mathrm{~L} / \mathrm{h}=5$, Type $\mathrm{B}$.

Table 11: Dimensionless maximum transverse deflections of the FG sandwich C-S beams for different beam theories and gradation exponents, Type B.

\begin{tabular}{|c|c|c|c|c|c|c|c|c|c|c|c|}
\hline \multirow{3}{*}{ Theory } & \multirow{3}{*}{$P_{z}$} & \multicolumn{5}{|c|}{$\mathrm{L} / \mathrm{h}=5$} & \multicolumn{5}{|c|}{$\mathrm{L} / \mathrm{h}=20$} \\
\hline & & & & $p_{x}$ & & & & & $\overline{p_{x}}$ & & \\
\hline & & 0 & 0.5 & 1 & 2 & 5 & 0 & 0.5 & 1 & 2 & 5 \\
\hline \multirow{5}{*}{ EBT } & $\overline{0}$ & 1.1972 & 1.2509 & 1.3002 & 1.3849 & $\overline{\mid 1.5421}$ & 1.1972 & $\begin{array}{l}1.2509 \\
\end{array}$ & 1.3002 & 1.3849 & $\overline{\mid 1.5421}$ \\
\hline & 0.5 & 1.3709 & 1.4235 & 1.4708 & 1.5508 & 1.6948 & 1.3709 & 1.4235 & \begin{tabular}{|l|}
1.4708 \\
\end{tabular} & 1.5508 & 1.6948 \\
\hline & 1 & 1.4802 & 1.5294 & 1.5733 & 1.6462 & 1.7748 & 1.4802 & 1.5294 & 1.5733 & 1.6462 & 1.7748 \\
\hline & 2 & 1.6179 & 1.6604 & 1.6977 & 1.7584 & 1.8628 & 1.6179 & 1.6604 & $\begin{array}{l}1.6977 \\
\end{array}$ & 1.7584 & 1.8628 \\
\hline & 5 & 1.8179 & 1.8475 & 1.8729 & 1.9132 & 1.9799 & 1.8179 & 1.8475 & $\begin{array}{l}1.8729 \\
\end{array}$ & 1.9132 & 1.9799 \\
\hline \multirow{5}{*}{ TBT } & 0 & 1.5275 & 1.5885 & 1.6442 & 1.7397 & 1.9174 & 1.2178 & 1.2720 & 1.3217 & 1.4070 & 1.5655 \\
\hline & 0.5 & 1.7859 & 1.8460 & 1.9001 & 1.9911 & 2.1558 & 1.3969 & 1.4499 & \begin{tabular}{|l|l}
1.4977 \\
\end{tabular} & 1.5783 & 1.7236 \\
\hline & 1 & 1.9561 & 2.0127 & 2.0632 & 2.1467 & 2.2953 & 1.5100 & 1.5596 & $\begin{array}{l}1.6039 \\
\end{array}$ & 1.6774 & 1.8073 \\
\hline & 2 & 2.1757 & 2.2250 & 2.2682 & 2.3387 & 2.4604 & 1.6528 & 1.6957 & 1.7338 & 1.7947 & 1.9001 \\
\hline & 5 & 2.4917 & 2.5263 & 2.5559 & 2.6030 & 2.6817 & 1.8590 & 1.8898 & 1.9156 & 1.9563 & 2.0237 \\
\hline \multirow{5}{*}{ RBT } & 0 & 1.5883 & 1.6470 & 1.7009 & 1.7931 & 1.9638 & 1.2217 & 1.2758 & $\begin{array}{l}1.3253 \\
\end{array}$ & 1.4105 & 1.5685 \\
\hline & 0.5 & 1.8876 & 1.9454 & 1.9974 & 2.0850 & 2.2426 & 1.4034 & 1.4562 & 1.5039 & 1.5843 & 1.7292 \\
\hline & 1 & 2.1013 & 2.1556 & 2.2042 & 2.2847 & 2.4263 & 1.5193 & 1.5687 & 1.6129 & 1.6861 & 1.8158 \\
\hline & 2 & 2.3989 & 2.4462 & 2.4879 & 2.5559 & 2.6725 & 1.6670 & 1.7097 & $\begin{array}{l}1.7474 \\
\end{array}$ & 1.8086 & 1.9136 \\
\hline & 5 & 2.8563 & 2.8897 & 2.9187 & 2.9650 & 3.0404 & 1.8833 & 1.9131 & \begin{tabular}{|l|}
1.9387 \\
\end{tabular} & 1.9794 & 2.0466 \\
\hline
\end{tabular}



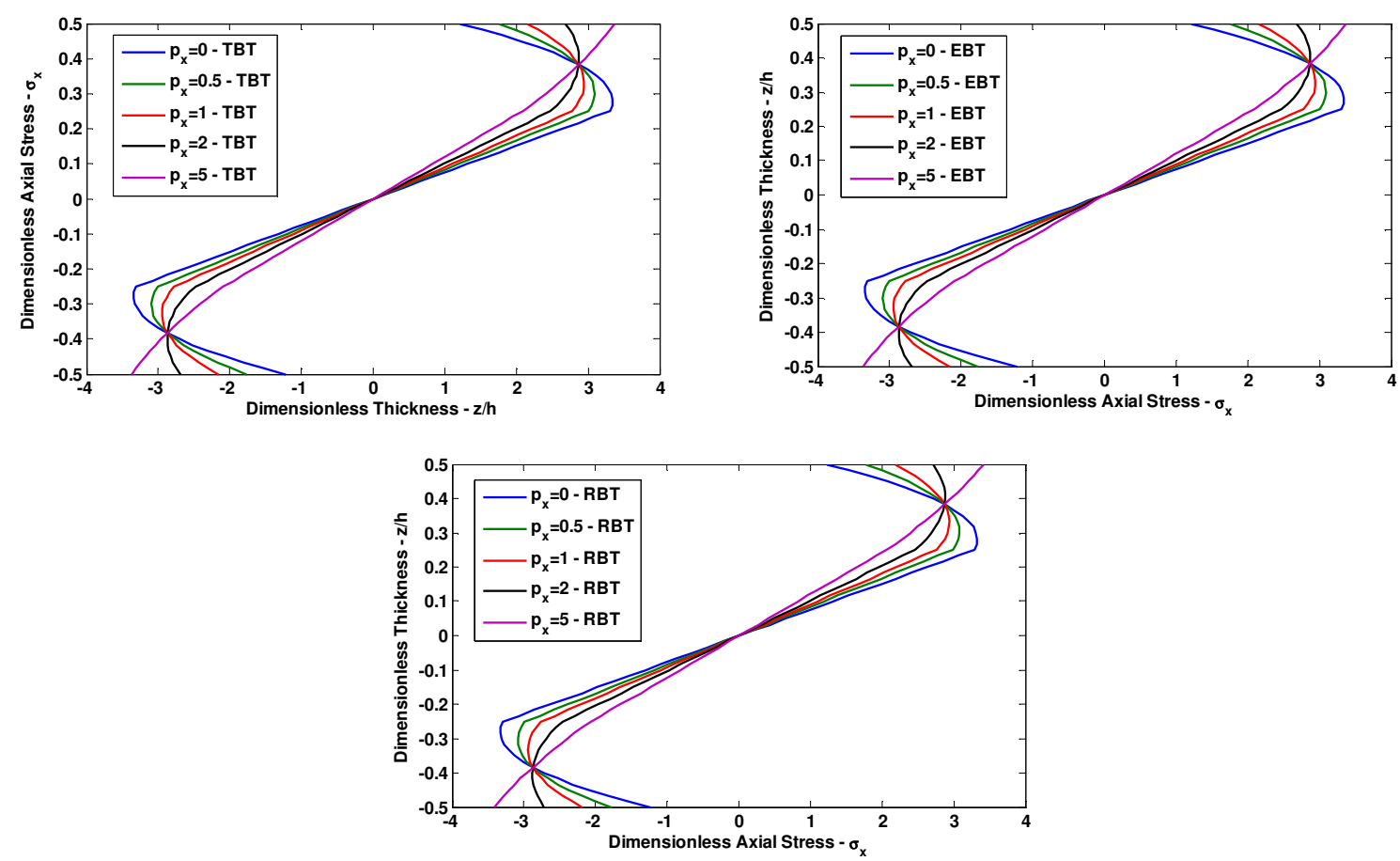

Fig. 5: Dimensionless axial stress $\bar{\sigma}_{x}\left(\frac{L}{2}, z\right)$ through the thickness of the FG sandwich S-S beams for different beam theories and $\mathrm{p}_{z}=1, \mathrm{~L} / \mathrm{h}=5$, Type $\mathrm{C}$.

Table 12: Dimensionless maximum transverse deflections of the FG sandwich C-S beams for different beam theories and gradation exponents, Type $\mathrm{C}$.

\begin{tabular}{|c|c|c|c|c|c|c|c|c|c|c|c|}
\hline \multirow{3}{*}{ Theory } & \multirow{3}{*}{$P_{z}$} & \multicolumn{5}{|c|}{$\mathrm{L} / \mathrm{h}=5$} & \multicolumn{5}{|c|}{$\mathrm{L} / \mathrm{h}=20$} \\
\hline & & & & $p_{x}$ & & & & & $p_{x}$ & & \\
\hline & & 0 & 0.5 & 1 & 2 & 5 & 0 & 0.5 & 1 & 2 & 5 \\
\hline \multirow{5}{*}{ EBT } & $\overline{\overline{0}}$ & 4.1833 & 3.2757 & $=2.8064$ & 2.3134 & 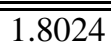 & 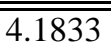 & 3.2757 & 2.8064 & 2.3134 & $\overline{\overline{1.8024}}$ \\
\hline & 0.5 & 2.5806 & 2.2787 & 2.0851 & 1.8504 & 1.5700 & 2.5806 & 2.2787 & 2.0851 & 1.8504 & 1.5700 \\
\hline & 1 & 2.1129 & 1.9407 & 1.8217 & 1.6682 & 1.4725 & 2.1129 & 1.9407 & 1.8217 & 1.6682 & 1.4725 \\
\hline & 2 & 1.7506 & 1.6608 & 1.5944 & 1.5039 & 1.3807 & 1.7506 & 1.6608 & 1.5944 & 1.5039 & 1.3807 \\
\hline & 5 & 1.4540 & 1.4182 & 1.3901 & 1.3495 & 1.2906 & 1.4540 & 1.4182 & 1.3901 & 1.3495 & 1.2906 \\
\hline \multirow{5}{*}{ TBT } & 0 & 4.7410 & 3.7939 & 3.2975 & 2.7688 & 2.2070 & 4.2181 & 3.3081 & 2.8371 & 2.3419 & 1.8276 \\
\hline & 0.5 & 3.0343 & 2.7142 & 2.5072 & 2.2535 & 1.9442 & 2.6090 & 2.3059 & 2.1115 & 1.8756 & 1.5934 \\
\hline & 1 & 2.5279 & 2.3442 & 2.2163 & 2.0499 & 1.8339 & 2.1388 & 1.9660 & 1.8463 & 1.6920 & 1.4950 \\
\hline & 2 & 2.1329 & 2.0365 & 1.9648 & 1.8665 & 1.7305 & 1.7745 & 1.6843 & 1.6175 & 1.5265 & 1.4025 \\
\hline & 5 & 1.8084 & 1.7697 & 1.7392 & 1.6950 & 1.6300 & 1.4762 & 1.4402 & 1.4119 & 1.3711 & 1.3118 \\
\hline \multirow{5}{*}{ RBT } & 0 & 4.6935 & 3.7566 & 3.2693 & 2.7544 & 2.2180 & 4.2152 & 3.3058 & 2.8354 & 2.3411 & 1.8284 \\
\hline & 0.5 & 3.0378 & 2.7211 & 2.5175 & 2.2690 & 1.9735 & 2.6092 & 2.3064 & 2.1122 & 1.8767 & 1.5953 \\
\hline & 1 & 2.5490 & 2.3674 & 2.2416 & 2.0787 & 1.8713 & 2.1402 & 1.9675 & 1.8480 & 1.6939 & 1.4975 \\
\hline & 2 & 2.1695 & 2.0743 & 2.0035 & 1.9069 & 1.7759 & 1.7768 & 1.6867 & 1.6200 & 1.5291 & 1.4054 \\
\hline & 5 & 1.8590 & 1.8204 & 1.7901 & 1.7466 & 1.6836 & 1.4794 & 1.4434 & 1.4152 & 1.3744 & 1.3152 \\
\hline
\end{tabular}



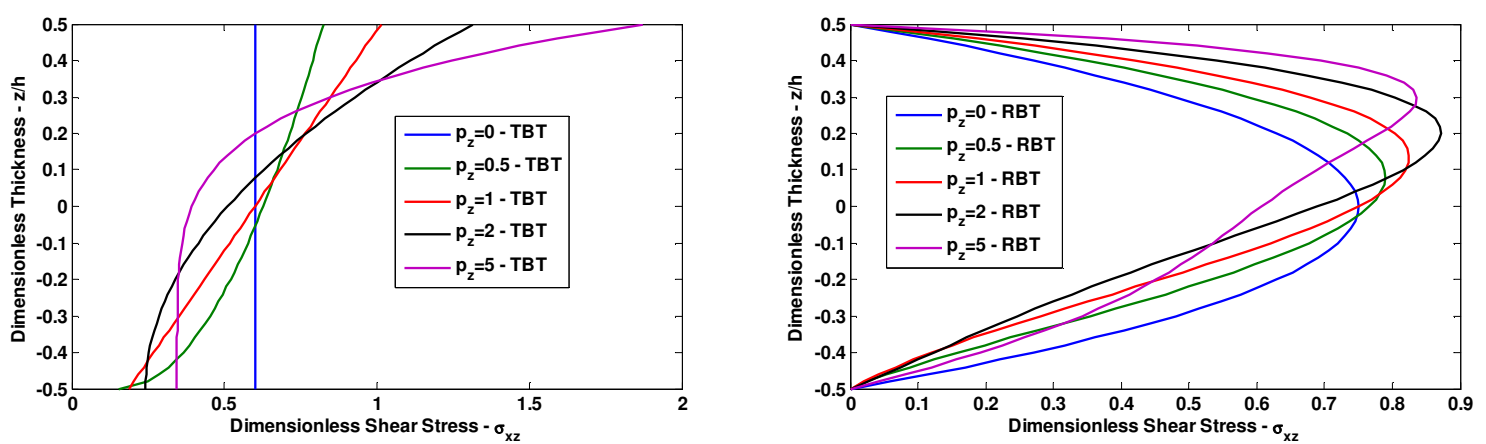

(a)
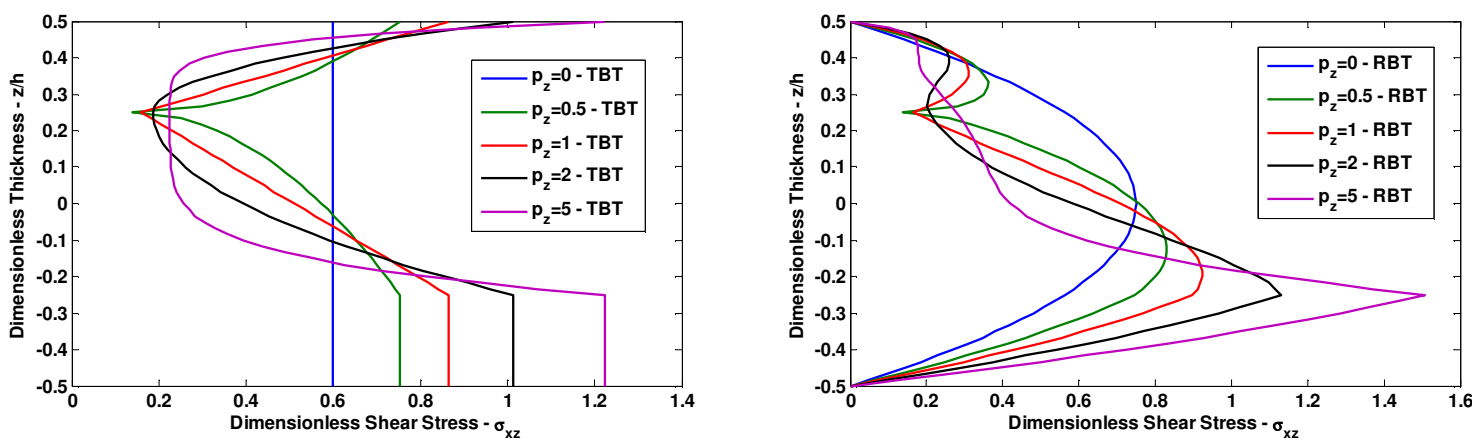

(b)
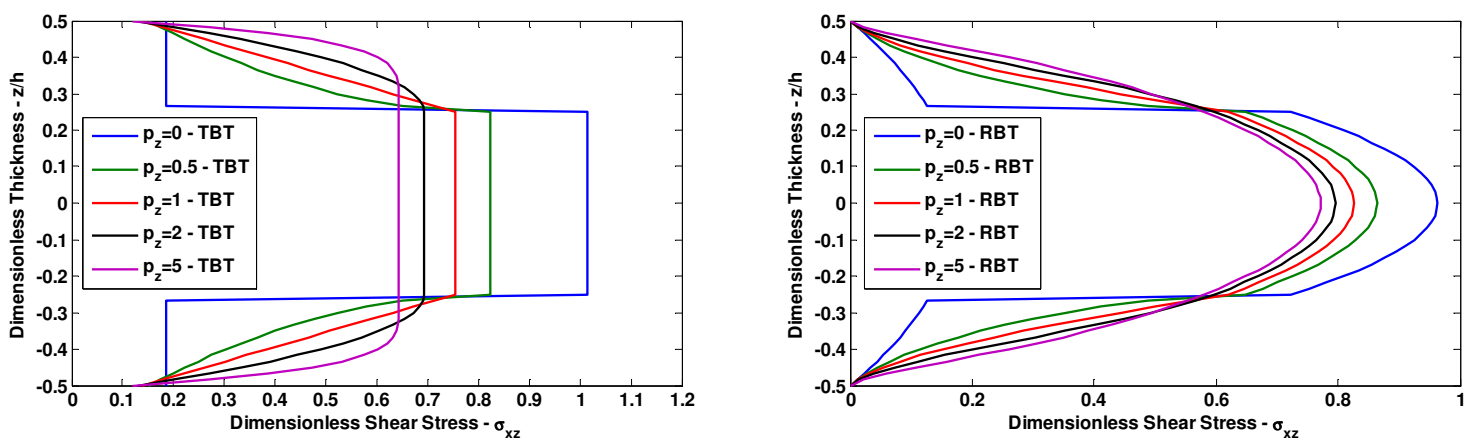

(c)

Fig. 6: Dimensionless transverse shear stress $\bar{\sigma}_{x z}(0, z)$ through the thickness of the FG sandwich S-S beams for different beam theories and $\mathrm{p}_{x}=1, \mathrm{~L} / \mathrm{h}=5$; a) Type $\left.\mathrm{A}, \mathbf{b}\right)$ Type B, c) Type C. 

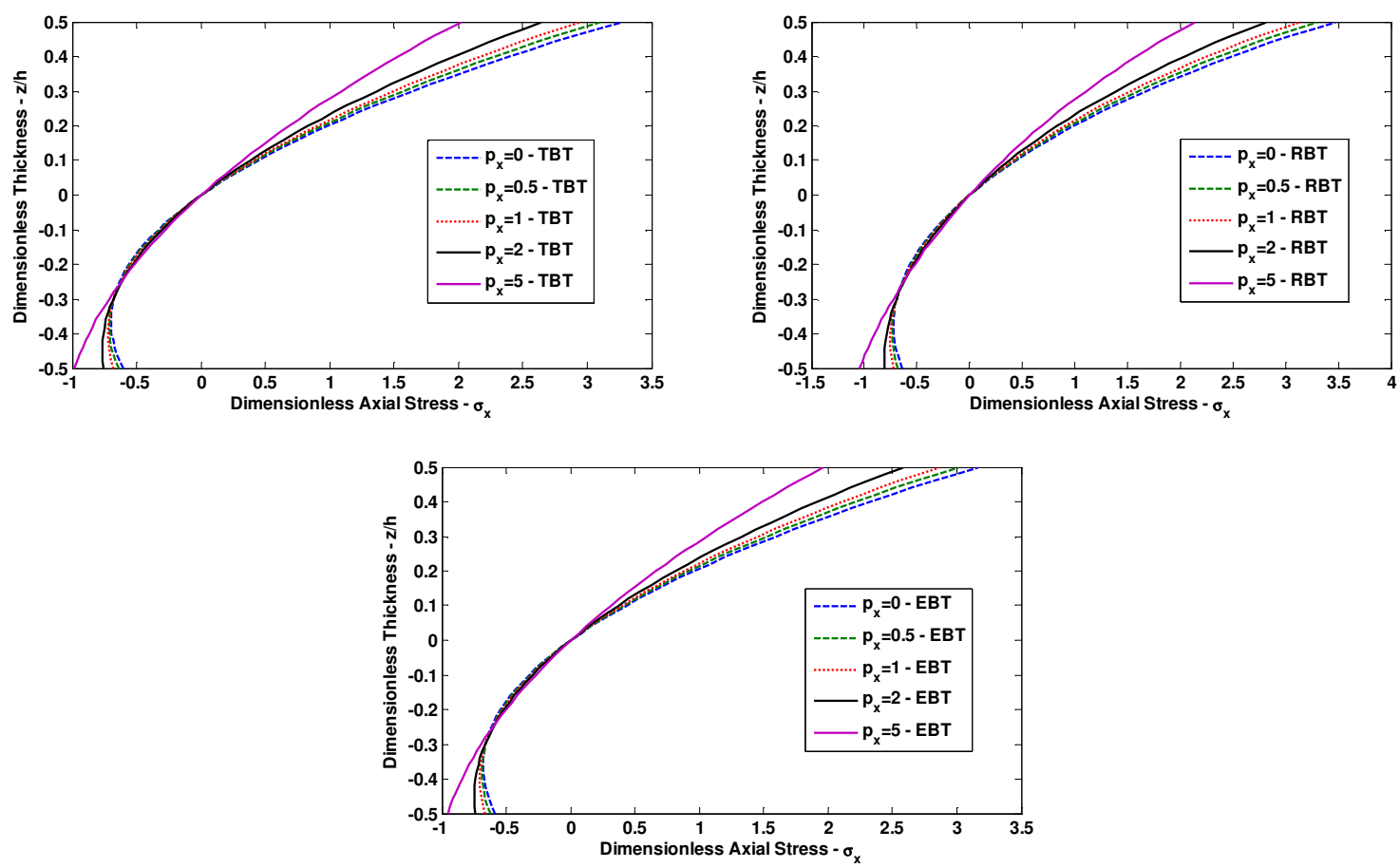

Fig. 7: Dimensionless axial stress $\bar{\sigma}_{x}\left(\frac{L}{2}, z\right)$ through the thickness of the FG sandwich C-S beams for different beam theories and $\mathrm{p}_{z}=1, \mathrm{~L} / \mathrm{h}=5$, Type A.
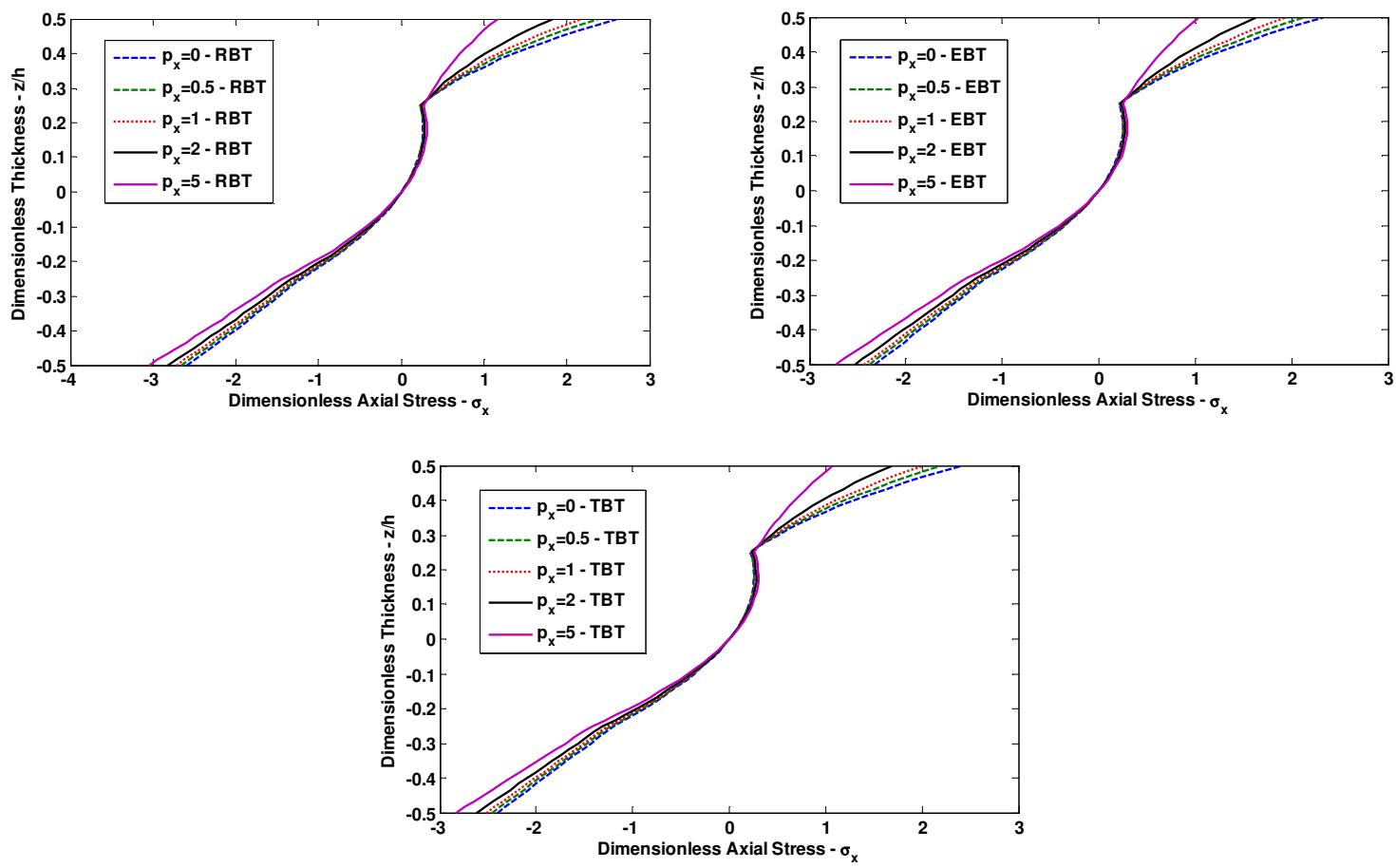

Fig. 8: Dimensionless axial stress $\bar{\sigma}_{x}\left(\frac{L}{2}, z\right)$ through the thickness of the FG sandwich C-S beams for different beam theories and $\mathrm{p}_{z}=1, \mathrm{~L} / \mathrm{h}=5$, Type B. 

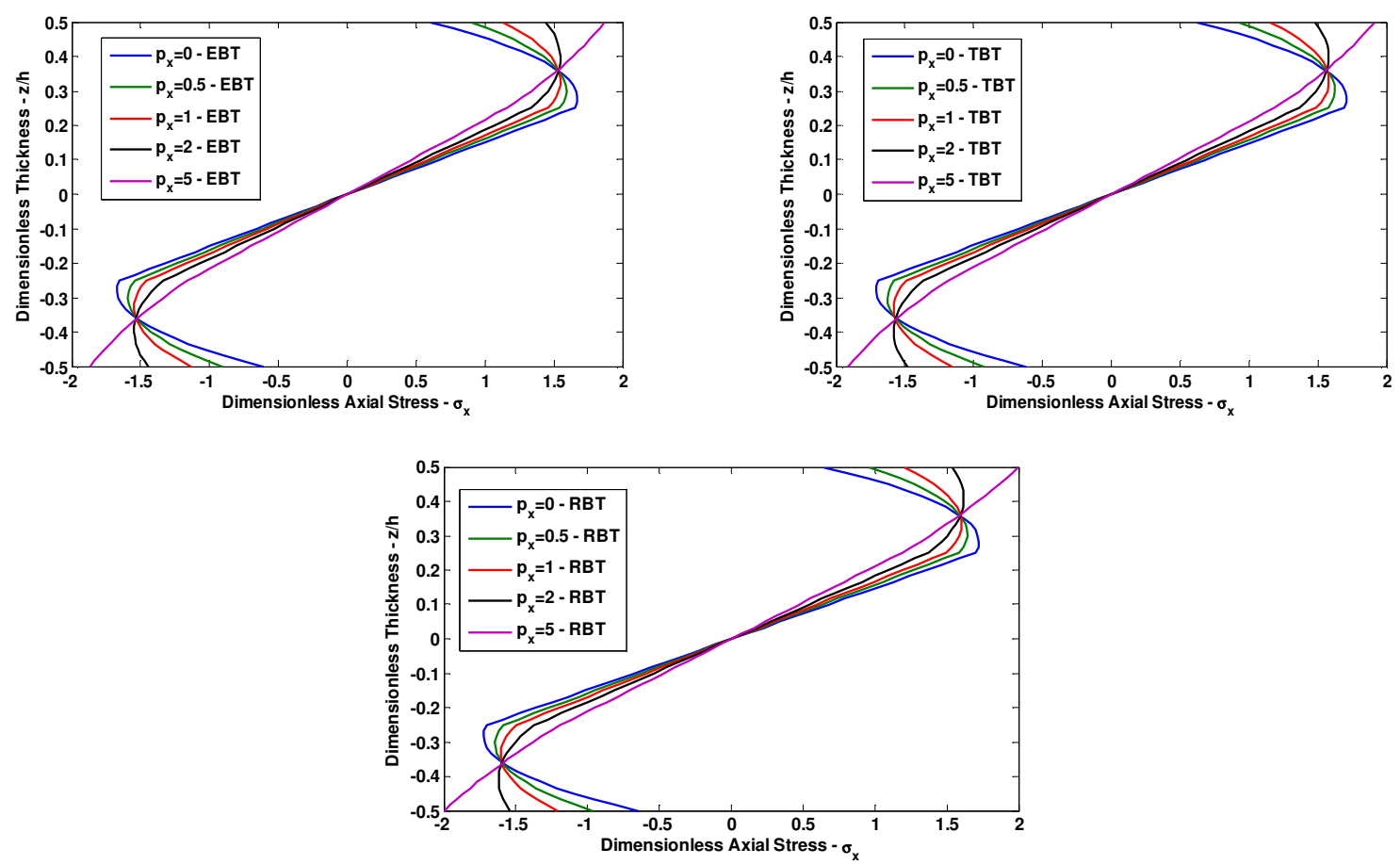

Fig. 9: Dimensionless axial stress $\bar{\sigma}_{x}\left(\frac{L}{2}, z\right)$ through the thickness of the FG sandwich C-S beams for different beam theories and $\mathrm{p}_{z}=1, \mathrm{~L} / \mathrm{h}=5$, Type $\mathrm{C}$.

Table 13: Dimensionless maximum transverse deflections of the FG sandwich C-C beams for different beam theories and gradation exponents, Type A.

\begin{tabular}{|c|c|c|c|c|c|c|c|c|c|c|c|}
\hline \multirow{3}{*}{ Theory } & \multirow{3}{*}{$P_{z}$} & \multicolumn{5}{|c|}{$\mathrm{L} / \mathrm{h}=5$} & \multicolumn{5}{|c|}{$\mathrm{L} / \mathrm{h}=20$} \\
\hline & & \multicolumn{5}{|c|}{$\overline{p_{x}}$} & \multicolumn{5}{|c|}{$\overline{p_{x}}$} \\
\hline & & 0 & 0.5 & 1 & 2 & 5 & 0 & 0.5 & 1 & 2 & 5 \\
\hline \multirow{5}{*}{ EBT } & 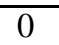 & 0.5757 & 0.6526 & 0.7352 & 0.9111 & 1.4013 & 0.5757 & 0.6526 & 0.7352 & 0.9111 & $\begin{array}{l}1.4013 \\
\end{array}$ \\
\hline & 0.5 & 0.8259 & 0.9238 & 1.0250 & 1.2279 & 1.7179 & 0.8259 & 0.9238 & 1.0250 & 1.2279 & 1.7179 \\
\hline & 1 & 0.9722 & 1.0791 & 1.1871 & 1.3972 & 1.8722 & 0.9722 & 1.0791 & 1.1871 & 1.3972 & 1.8722 \\
\hline & 2 & 1.1276 & 1.2414 & 1.3541 & 1.5664 & 2.0180 & 1.1276 & 1.2414 & 1.3541 & 1.5664 & 2.0180 \\
\hline & 5 & 1.3795 & 1.4992 & 1.6139 & 1.8199 & 2.2239 & 1.3795 & 1.4992 & 1.6139 & 1.8199 & 2.2239 \\
\hline \multirow{5}{*}{ TBT } & 0 & 0.8630 & 0.9793 & 1.1054 & 1.3781 & 2.1431 & 0.5936 & 0.6731 & 0.7583 & 0.9403 & 1.4477 \\
\hline & 0.5 & 1.2206 & 1.2206 & 1.5203 & 1.8316 & 2.5887 & 0.8506 & 0.9515 & 1.0559 & 1.2656 & 1.7724 \\
\hline & 1 & 1.4576 & 1.4576 & 1.7832 & 2.1056 & 2.8313 & 1.0003 & 1.1128 & 1.2244 & 1.4415 & 1.9322 \\
\hline & 2 & 1.7576 & 1.7576 & 2.1029 & 2.4249 & 3.0947 & 1.1670 & 1.2845 & 1.4009 & 1.6200 & 2.0854 \\
\hline & 5 & 2.2770 & 2.2770 & 2.6228 & 2.9182 & 3.4756 & 1.4356 & 1.5589 & 1.6770 & 1.8886 & 2.3022 \\
\hline \multirow{5}{*}{ RBT } & 0 & 0.9349 & 1.0616 & 1.1988 & 1.4952 & 2.3135 & 0.5981 & 0.6782 & 0.7642 & 0.9477 & 1.4586 \\
\hline & 0.5 & 1.3081 & 1.4666 & 1.6324 & 1.9694 & 2.7793 & 0.8561 & 0.9577 & 1.0629 & 1.2743 & 1.7845 \\
\hline & 1 & 1.5789 & $\begin{array}{l}.5789 \\
\end{array}$ & 1.9332 & 2.2820 & 3.0541 & 1.0101 & 1.1213 & 1.2338 & 1.4526 & 1.9463 \\
\hline & 2 & 1.9786 & 1.9786 & 2.3546 & 2.6978 & 3.3912 & 1.1808 & 1.2993 & 1.4166 & 1.6371 & 2.1040 \\
\hline & 5 & 2.7652 & 2.7652 & 3.1075 & 3.3916 & 3.9198 & 1.4661 & 1.5894 & 1.7072 & 1.9182 & 2.3299 \\
\hline
\end{tabular}


TBT
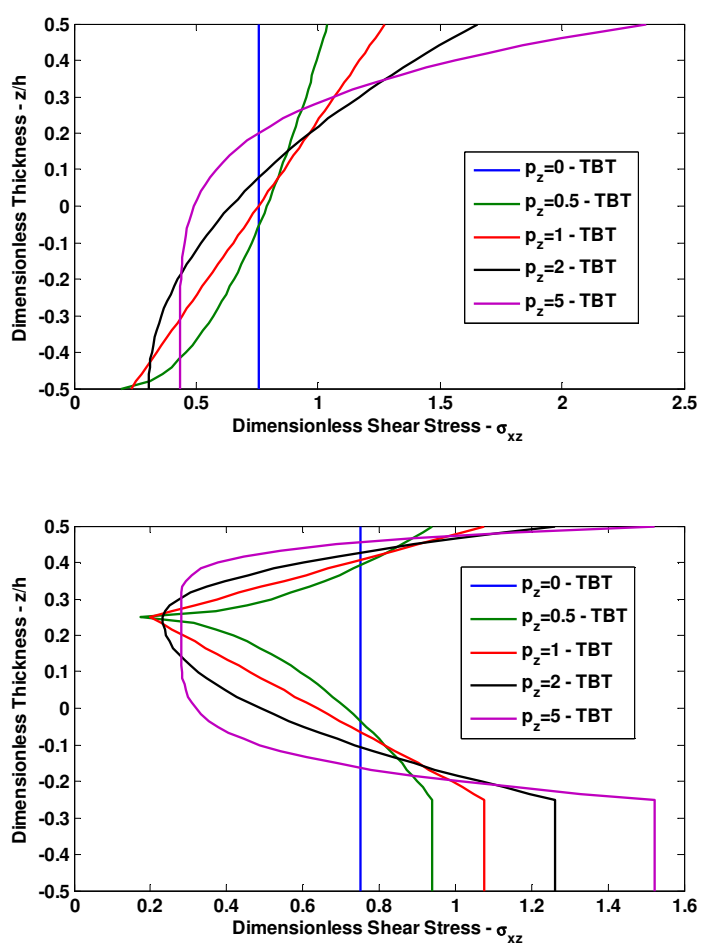

(b)

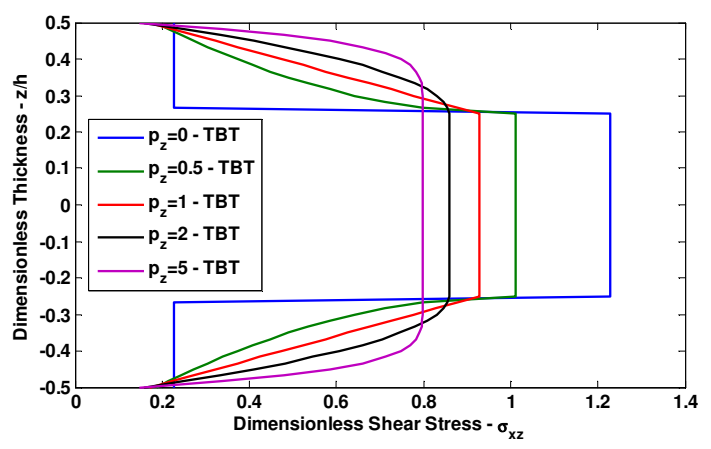

(c)

(a)

RBT
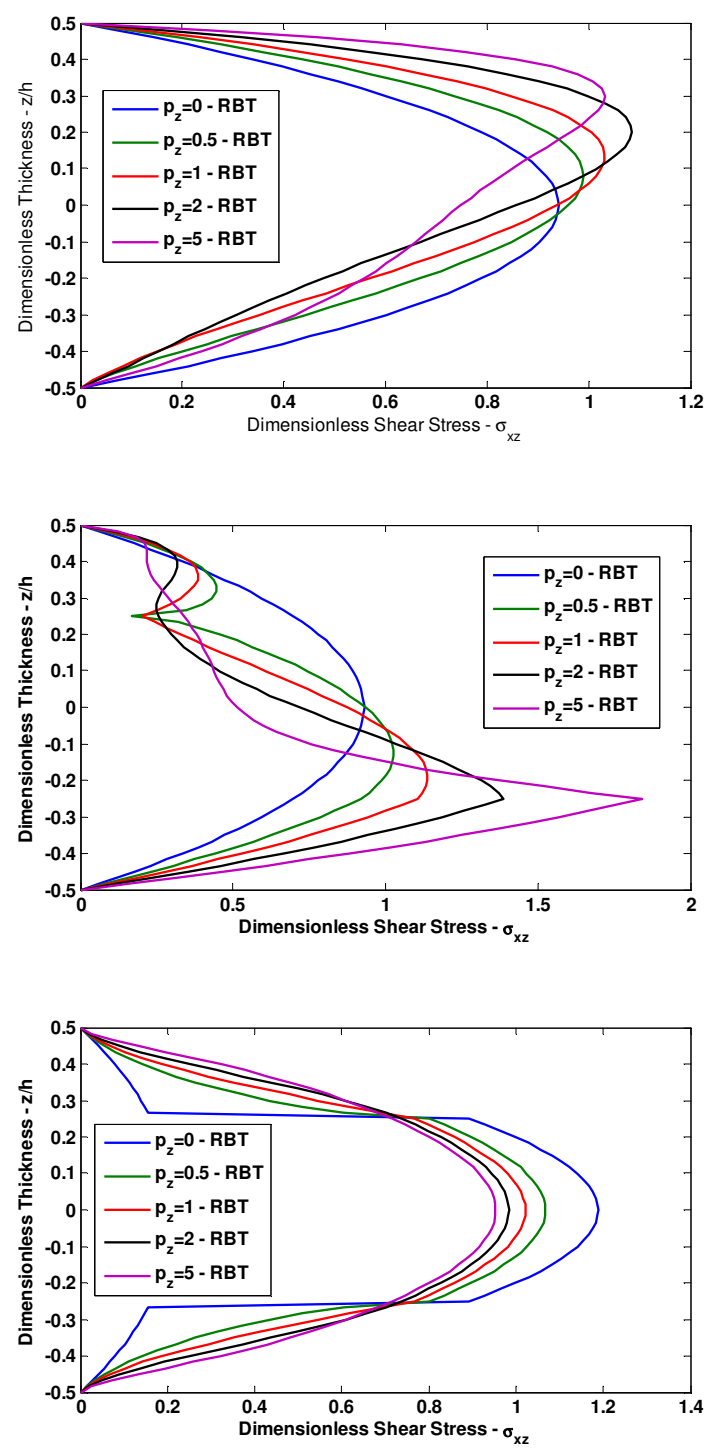

Fig. 10: Dimensionless transverse shear stress $\bar{\sigma}_{x z}(0, z)$ through the thickness of the FG sandwich C-S beams for different beam theories and $\mathrm{p}_{x}=1, \mathrm{~L} / \mathrm{h}=5$; a) Type $\left.\mathrm{A}, \mathbf{b}\right)$ Type $\mathrm{B}$, c) Type $\mathrm{C}$. 

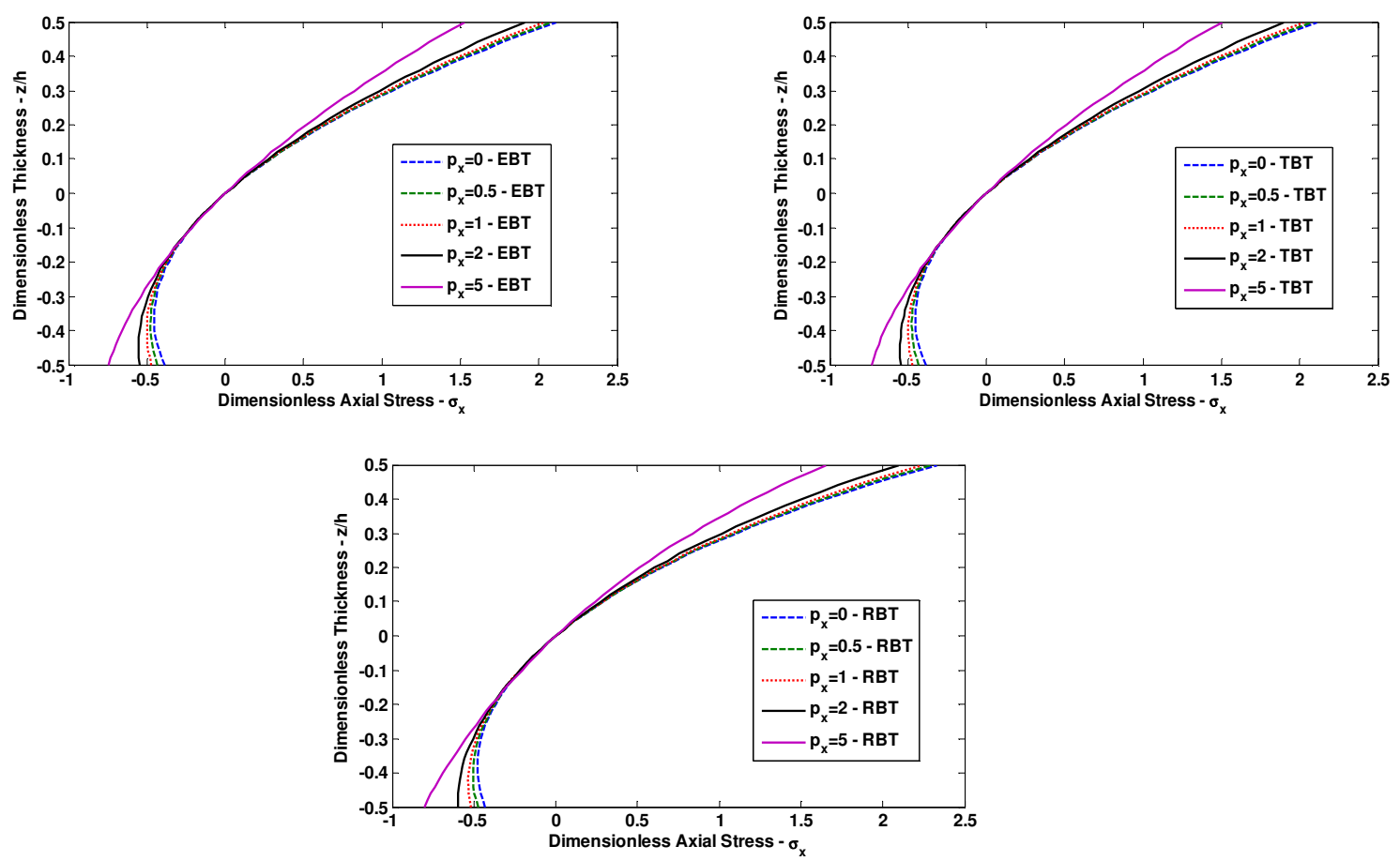

Fig. 11: Dimensionless axial stress $\bar{\sigma}_{x}\left(\frac{L}{2}, z\right)$ through the thickness of the FG sandwich C-C beams for different beam theories and $\mathrm{p}_{z}=1, \mathrm{~L} / \mathrm{h}=5$, Type $\mathrm{A}$.
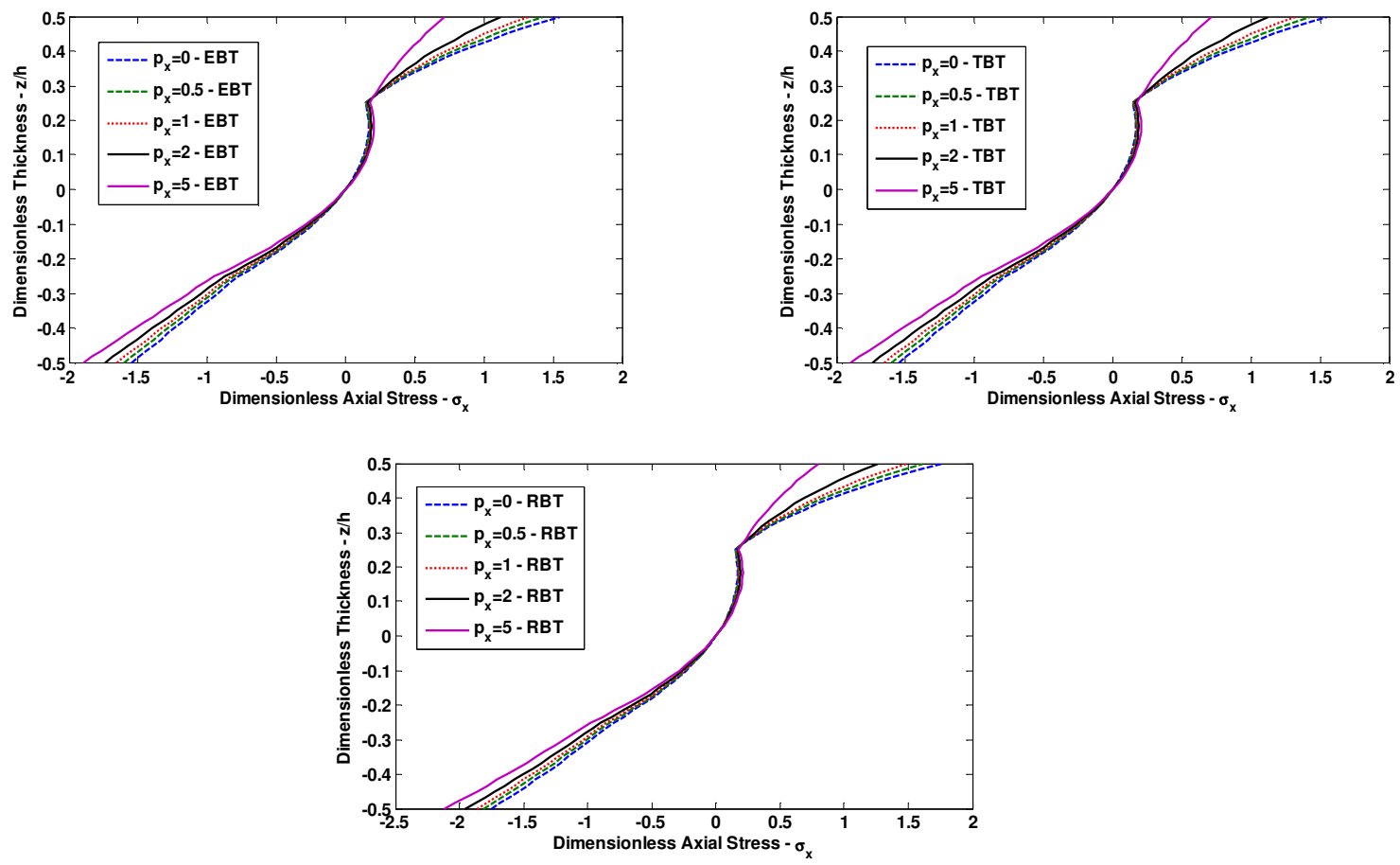

Fig. 12: Dimensionless axial stress $\bar{\sigma}_{x}\left(\frac{L}{2}, z\right)$ through the thickness of the FG sandwich C-C beams for different beam theories and $\mathrm{p}_{z}=1, \mathrm{~L} / \mathrm{h}=5$, Type $\mathrm{B}$. 
Table 14: Dimensionless maximum transverse deflections of the FG sandwich C-C beams for different beam theories and gradation exponents, Type B.

\begin{tabular}{|c|c|c|c|c|c|c|c|c|c|c|c|}
\hline \multirow{3}{*}{ Theory } & \multirow{3}{*}{$P_{z}$} & \multicolumn{5}{|c|}{$\mathrm{L} / \mathrm{h}=5$} & \multicolumn{5}{|c|}{$\mathrm{L} / \mathrm{h}=20$} \\
\hline & & \multicolumn{5}{|c|}{$p_{x}$} & \multicolumn{5}{|c|}{$p_{x}$} \\
\hline & & 0 & 0.5 & 1 & 2 & 5 & 0 & 0.5 & 1 & 2 & 5 \\
\hline \multirow{5}{*}{ EBT } & 0 & 0.5757 & 0.6063 & 0.6335 & 0.6779 & 0.7527 & 0.5757 & 0.6063 & 0.6335 & 0.6779 & 0.7527 \\
\hline & 0.5 & 0.6592 & 0.6891 & 0.7152 & 0.7568 & 0.8251 & 0.6592 & 0.6891 & 0.7152 & 0.7568 & 0.8251 \\
\hline & 1 & 0.7117 & 0.7397 & 0.7638 & 0.8016 & 0.8624 & 0.7117 & 0.7397 & 0.7638 & 0.8016 & 0.8624 \\
\hline & 2 & 0.7780 & 0.8021 & 0.8225 & 0.8539 & 0.9029 & 0.7780 & 0.8021 & 0.8225 & 0.8539 & 0.9029 \\
\hline & 5 & 0.8741 & 0.8909 & 0.9046 & 0.9253 & 0.9565 & 0.8741 & 0.8909 & 0.9046 & 0.9253 & 0.9565 \\
\hline \multirow{5}{*}{ TBT } & 0 & 0.8630 & 0.9022 & 0.9366 & 0.9919 & 1.0834 & 0.5936 & 0.6248 & 0.6525 & 0.6976 & 0.7734 \\
\hline & 0.5 & 1.0202 & 1.0590 & 1.0925 & 1.1453 & 1.2303 & 0.6818 & 0.7122 & 0.7388 & 0.7811 & 0.8504 \\
\hline & 1 & 1.1258 & 1.1625 & 1.1938 & 1.2424 & 1.3191 & 0.7376 & 0.7661 & 0.7907 & 0.8292 & 0.8909 \\
\hline & 2 & 1.2633 & 1.2953 & 1.3223 & 1.3633 & 1.4263 & 0.8083 & 0.8329 & 0.8537 & 0.8857 & 0.9356 \\
\hline & 5 & 1.4604 & 1.4829 & 1.5013 & 1.5288 & 1.5696 & 0.9107 & 0.9279 & 0.9419 & 0.9631 & 0.9948 \\
\hline \multirow{5}{*}{ RBT } & 0 & 0.9349 & 0.9703 & 1.0016 & 1.0519 & 1.1357 & 0.5981 & 0.6291 & 0.6565 & 0.7013 & 0.7767 \\
\hline & 0.5 & 1.1355 & 1.1698 & 1.1997 & 1.2469 & 1.3236 & 0.6890 & 0.7191 & 0.7455 & 0.7875 & 0.8563 \\
\hline & 1 & 1.2853 & 1.3174 & 1.3449 & 1.3880 & 1.4565 & 0.7476 & 0.7758 & 0.8001 & 0.8383 & 0.8995 \\
\hline & 2 & 1.5005 & 1.5282 & 1.5515 & 1.5874 & 1.6432 & 0.8231 & 0.8474 & 0.8680 & 0.8997 & 0.9492 \\
\hline & 5 & 1.8365 & 1.8558 & 1.8716 & 1.8954 & 1.9312 & 0.9342 & 0.9512 & 0.9651 & 0.9860 & 1.0174 \\
\hline
\end{tabular}

Table 15: Dimensionless maximum transverse deflections of the FG sandwich C-C beams for different beam theories and gradation exponents, Type $\mathrm{C}$.

\begin{tabular}{|c|c|c|c|c|c|c|c|c|c|c|c|}
\hline \multirow{3}{*}{ Theory } & \multirow{3}{*}{$P_{z}$} & \multicolumn{5}{|c|}{$\mathrm{L} / \mathrm{h}=5$} & \multicolumn{5}{|c|}{$\mathrm{L} / \mathrm{h}=20$} \\
\hline & & \multicolumn{5}{|c|}{$p_{x}$} & \multicolumn{5}{|c|}{$p_{x}$} \\
\hline & & 0 & 0.5 & 1 & 2 & 5 & 0 & 0.5 & 1 & 2 & 5 \\
\hline \multirow{5}{*}{ EBT } & 0 & 2.0115 & 1.5188 & 1.2873 & 1.0592 & 0.8371 & 2.0115 & 1.5188 & 1.2873 & 1.0592 & 0.8371 \\
\hline & 0.5 & 1.2409 & 1.0739 & 0.9749 & 0.8625 & 0.7380 & 1.2409 & 1.0739 & 0.9749 & 0.8625 & 0.7380 \\
\hline & 1 & 1.0160 & 0.9201 & 0.8583 & 0.7837 & 0.6960 & 1.0160 & 0.9201 & 0.8583 & 0.7837 & 0.6960 \\
\hline & 2 & 0.8418 & 0.7914 & 0.7565 & 0.7119 & 0.6561 & 0.8418 & 0.7914 & 0.7565 & 0.7119 & 0.6561 \\
\hline & 5 & 0.6992 & 0.6789 & 0.6640 & 0.6437 & 0.6167 & 0.6992 & 0.6789 & 0.6640 & 0.6437 & 0.6167 \\
\hline \multirow{5}{*}{ TBT } & 0 & 2.4968 & 1.9625 & 1.7038 & 1.4429 & 1.1821 & 2.0418 & 1.5466 & 1.3134 & 1.0832 & 0.8587 \\
\hline & 0.5 & 1.6356 & 1.4492 & 1.3366 & 1.2066 & 1.0600 & 1.2656 & 1.0973 & 0.9975 & 0.8840 & 0.7581 \\
\hline & 1 & 1.3770 & 1.2687 & 1.1979 & 1.1113 & 1.0081 & 1.0385 & 0.9419 & 0.8796 & 0.8042 & 0.7155 \\
\hline & 2 & 1.1743 & 1.1169 & 1.0767 & 1.0248 & 0.9593 & 0.8625 & 0.8118 & 0.7765 & 0.7315 & 0.6751 \\
\hline & 5 & 1.0075 & 0.9841 & 0.9668 & 0.9432 & 0.9117 & 0.7184 & 0.6980 & 0.6829 & 0.6624 & 0.6352 \\
\hline \multirow{5}{*}{ RBT } & 0 & 2.4726 & 1.9585 & 1.7141 & 1.4699 & 1.2288 & 2.0403 & 1.5463 & 1.3140 & 1.0849 & 0.8616 \\
\hline & 0.5 & 1.6546 & 1.4771 & 1.3714 & 1.2505 & 1.1154 & 1.2667 & 1.0991 & 0.9997 & 0.8867 & 0.7616 \\
\hline & 1 & 1.4116 & 1.3092 & 1.2429 & 1.1625 & 1.0675 & 1.0407 & 0.9444 & 0.8824 & 0.8074 & 0.7192 \\
\hline & 2 & 1.2229 & 1.1688 & 1.1312 & 1.0831 & 1.0229 & 0.8656 & 0.8150 & 0.7800 & 0.7351 & 0.6791 \\
\hline & 5 & 1.0688 & 1.0469 & 1.0307 & 1.0088 & 0.9797 & 0.7222 & 0.7019 & 0.6869 & 0.6665 & 0.6394 \\
\hline
\end{tabular}



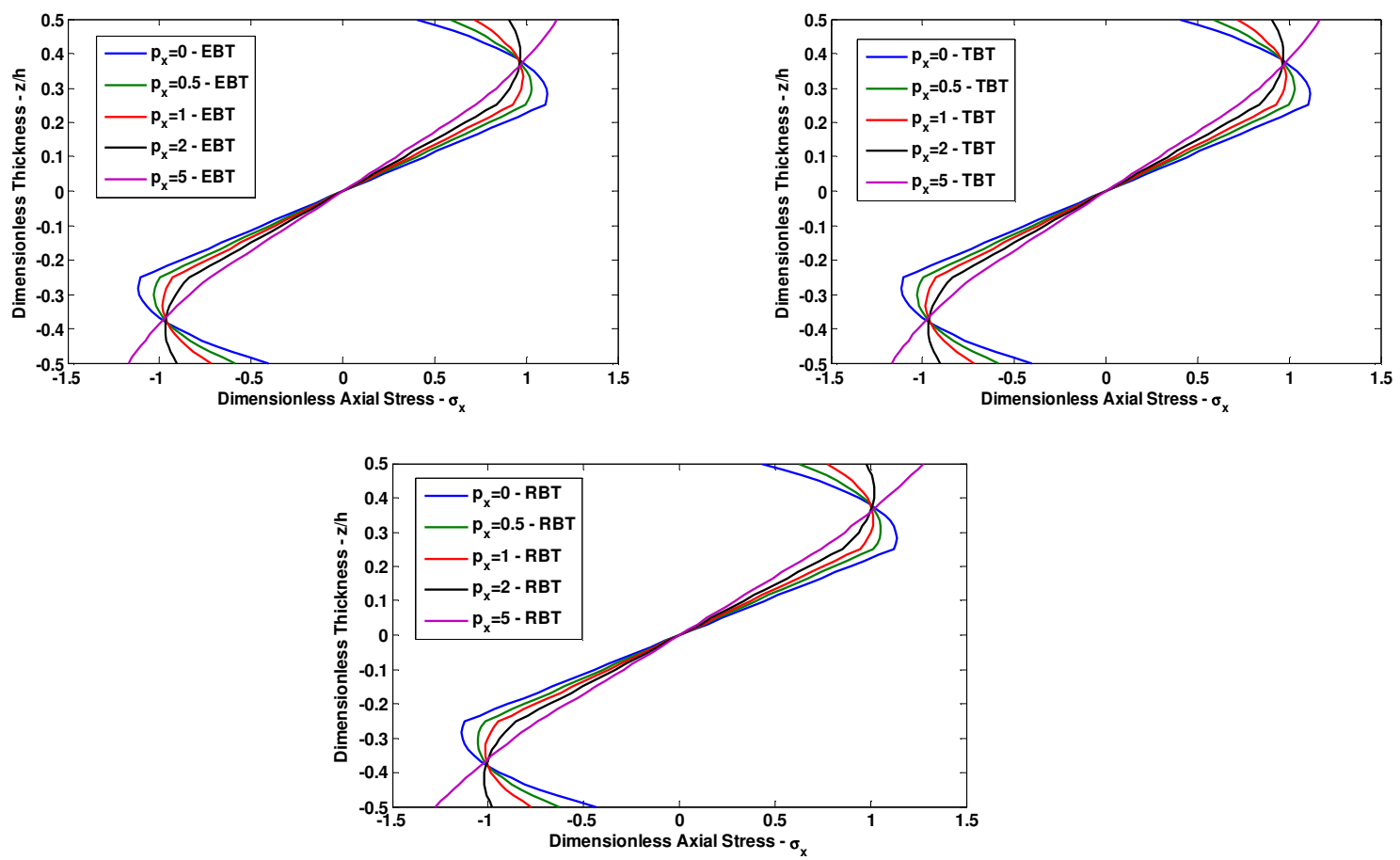

Fig. 13: Dimensionless axial stress $\bar{\sigma}_{x}\left(\frac{L}{2}, z\right)$ through the thickness of the FG sandwich C-C beams for different beam theories and $\mathrm{p}_{z}=1, \mathrm{~L} / \mathrm{h}=5$, Type $\mathrm{C}$.

Table 16: Dimensionless maximum transverse deflections of the FG sandwich C-F beams for different beam theories and gradation exponents, Type A.

\begin{tabular}{|c|c|c|c|c|c|c|c|c|c|c|c|}
\hline \multirow{3}{*}{ Theory } & \multirow{3}{*}{$P_{z}$} & \multicolumn{5}{|c|}{$\mathrm{L} / \mathrm{h}=5$} & \multicolumn{5}{|c|}{$\mathrm{L} / \mathrm{h}=20$} \\
\hline & & & & $p_{x}$ & & & & & $\overline{p_{x}}$ & & \\
\hline & & 0 & 0.5 & 1 & 2 & 5 & 0 & 0.5 & 1 & 2 & 5 \\
\hline \multirow{5}{*}{ EBT } & $\overline{0}$ & 7.6273 & 28.9038 & 30.2569 & .1880 & 43.3766 & 27.6273 & 28.9038 & 30.2569 & 33.1880 & $\overline{43.37 t}$ \\
\hline & 0.5 & 39.6379 & 41.2762 & 42.9831 & 46.5752 & 58.0486 & 39.6379 & 41.2762 & 42.9831 & 46.5752 & 8.04 \\
\hline & 1 & 46.6594 & 48.4568 & 50.3111 & 54.1524 & 65.9209 & 46.6594 & 48.4568 & 50.3111 & 54.1524 & 65.9209 \\
\hline & 2 & & 56.03 & 58.0053 & & & 541153 & & 58.0053 & & \\
\hline & 5 & 66.2059 & 68.2473 & 70.2987 & 74.3812 & 85.7469 & 66.2059 & 68.2473 & 70.2987 & 74.3812 & 85.7469 \\
\hline \multirow{5}{*}{ TBT } & 0 & 28.7 & 30.1 & 31.6081 & 34.7 & 45.7603 & 27.6955 & 28.9786 & 30.3386 & 33.2847 & 43.5233 \\
\hline & 0.5 & 41.2220 & 42.97 & 44.8103 & 48.6 & 60.9776 & 39.7309 & 41.3774 & 43.0928 & 46.7025 & 58.2278 \\
\hline & 1 & 48.6071 & 50.5364 & 52.5290 & 56.6586 & 69.2488 & 46.7747 & 48.5811 & 50.4447 & 54.3406 & 66.1242 \\
\hline & 2 & 56.6428 & 58.7133 & 60.8273 & 65. & 77.6946 & 54.2674 & 56.2016 & 58.1767 & 62.2026 & 74.0499 \\
\hline & 5 & 69.81 & 71.9908 & 74.1814 & & 90.4714 & 66.4261 & 68.4763 & 70.5362 & 74.6344 & 86.0349 \\
\hline \multirow{5}{*}{ RBT } & 0 & 29.3533 & 30.7283 & 32.1888 & 35.3567 & 46.3403 & 27.7318 & 29.0150 & 30.3752 & 33.3216 & 43.5599 \\
\hline & 0.5 & 41.9453 & 43.7064 & 45.5442 & 49.4 & 61.7203 & 39.7768 & 41.4235 & 43.1390 & 46.7490 & 58.2745 \\
\hline & 1 & 49.5762 & 51.5096 & 53.5077 & & 70.2252 & 46.8360 & 48.6426 & 50.5063 & 54.3665 & 66.1857 \\
\hline & 2 & 58.2352 & 60.3076 & 62.4221 & 66.7 & 79.2146 & 54.3683 & 56.3022 & 58.2772 & 62.3022 & 74.1455 \\
\hline & 5 & 72.9795 & 75.1213 & 77.2663 & 81.5052 & 93.1884 & 66.6268 & 68.6738 & 70.7304 & 74.8218 & 86.2054 \\
\hline
\end{tabular}


TBT
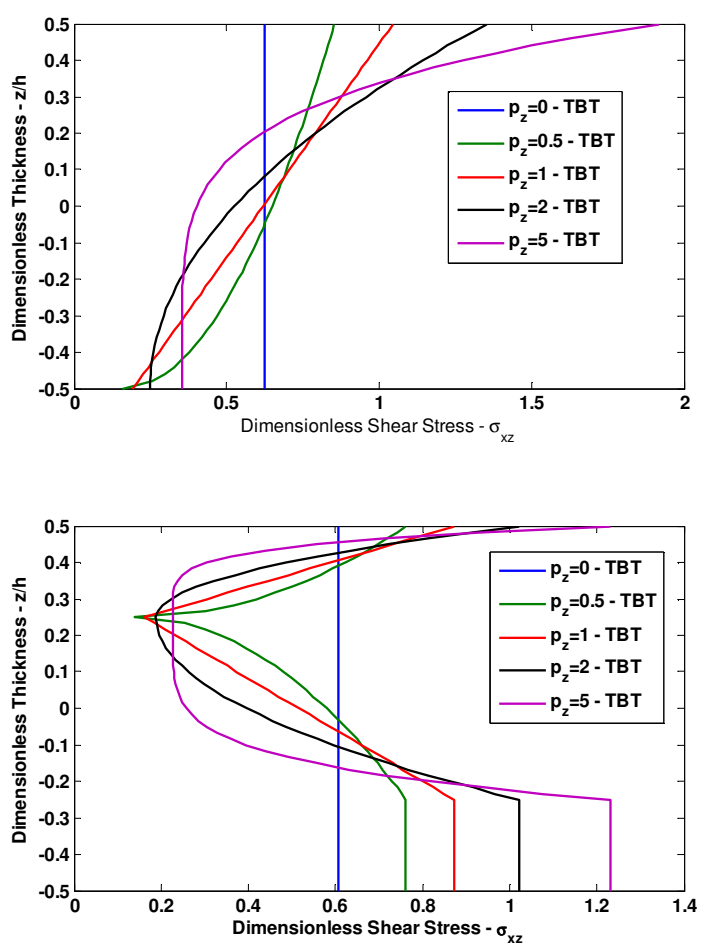

(b)

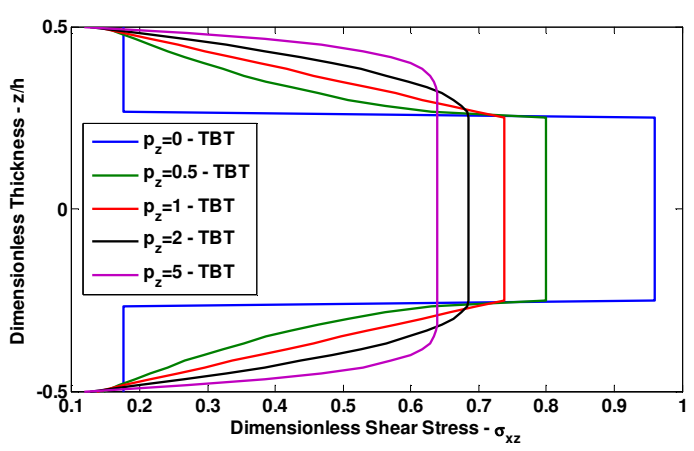

(a)

RBT
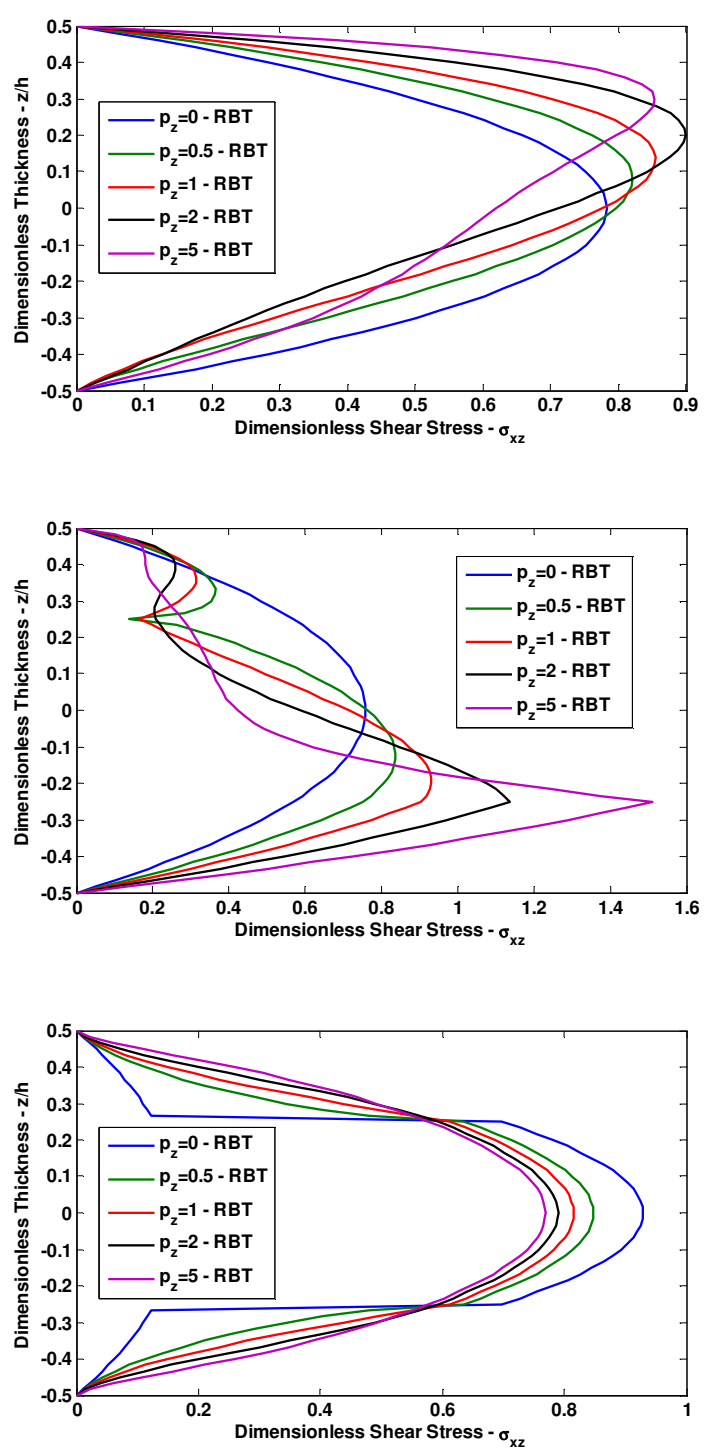

(c)

Fig. 14: Dimensionless transverse shear stress $\bar{\sigma}_{x z}(0, z)$ through the thickness of the FG sandwich C-C beams for different beam theories and $\mathrm{p}_{x}=1, \mathrm{~L} / \mathrm{h}=5$; a) Type A, b) Type B, c) Type C. 

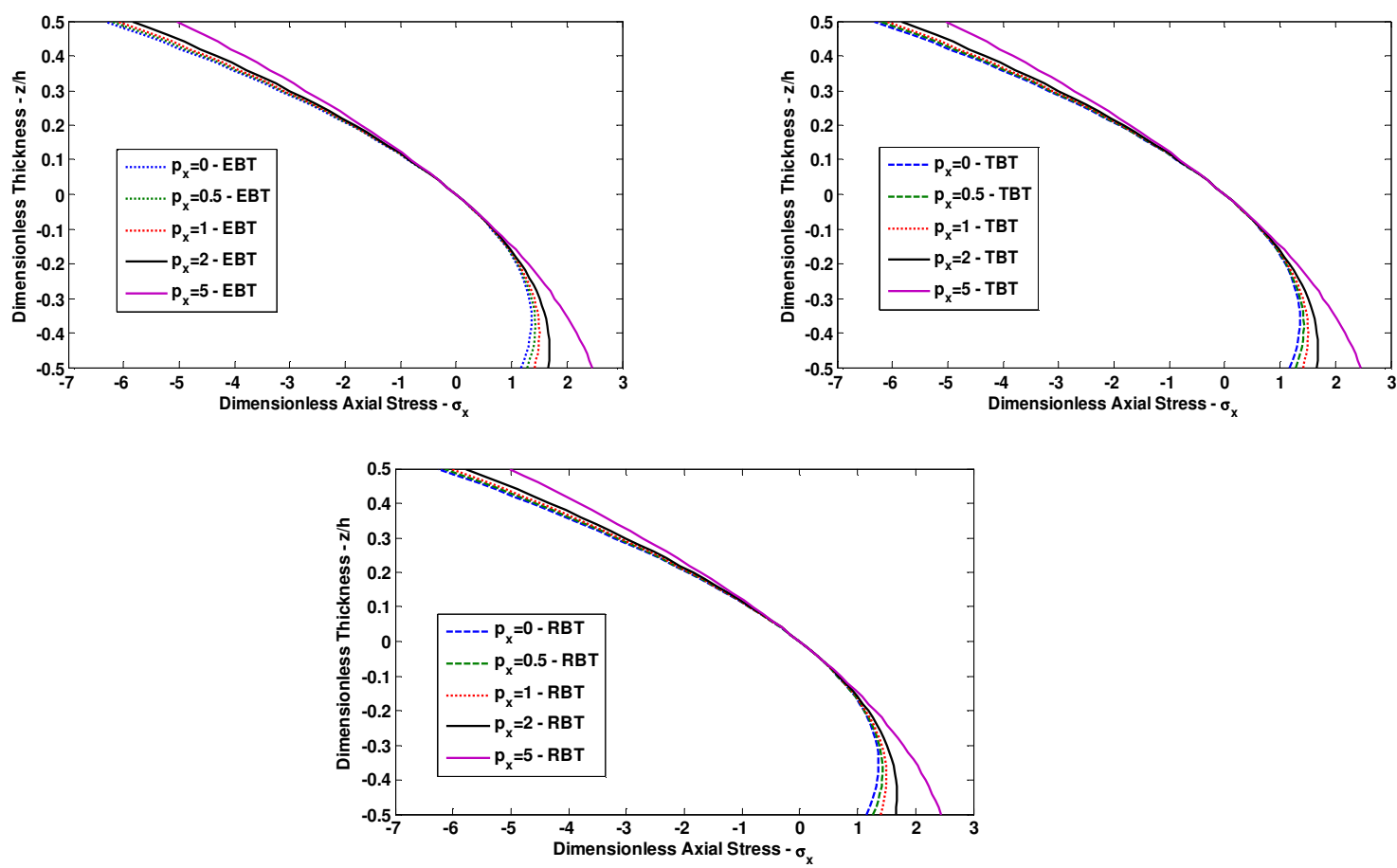

Fig. 15: Dimensionless axial stress $\bar{\sigma}_{x}\left(\frac{L}{2}, z\right)$ through the thickness of the FG sandwich C-F beams for different beam theories and $\mathrm{p}_{z}=1, \mathrm{~L} / \mathrm{h}=5$, Type A.
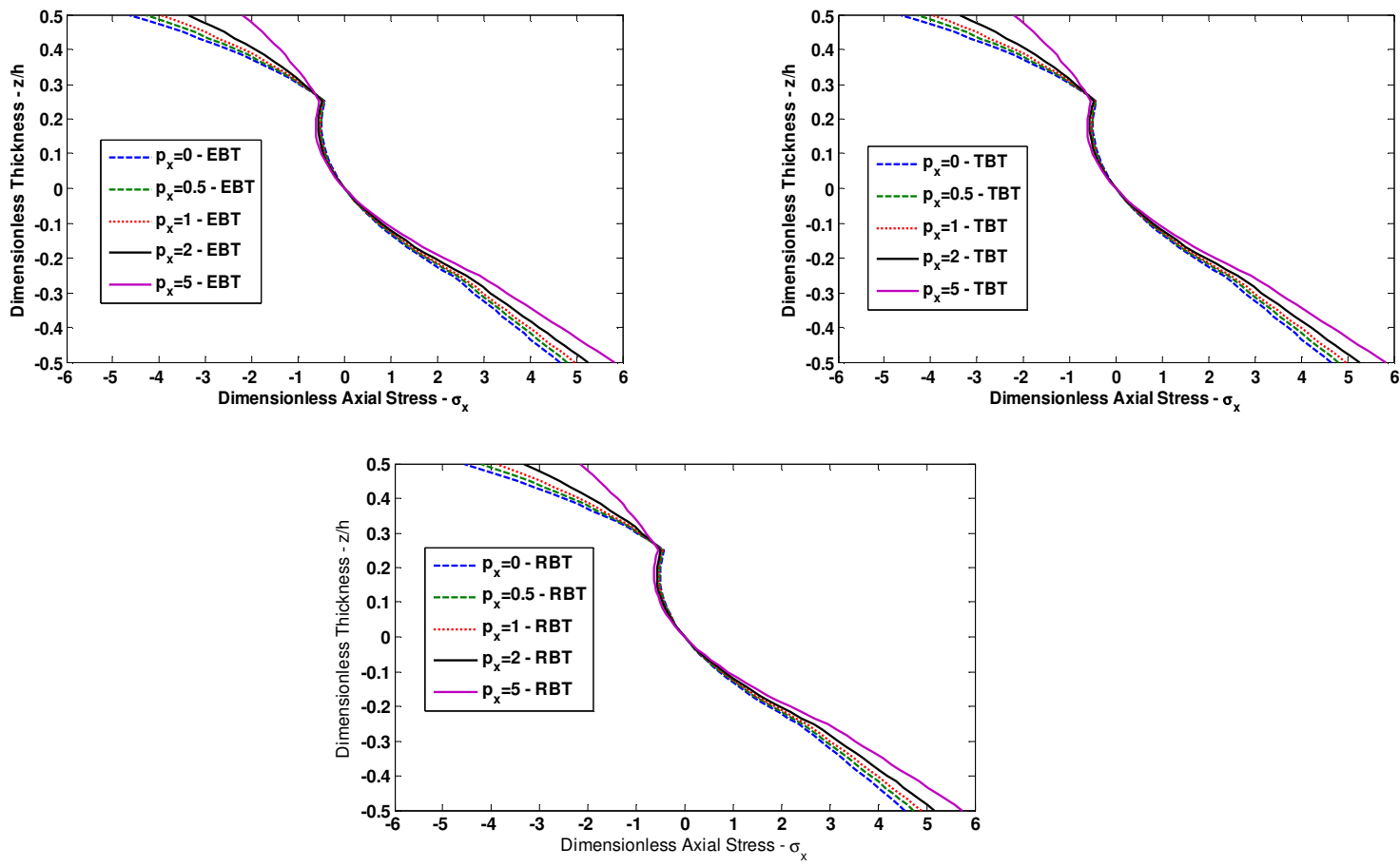

Fig. 16: Dimensionless axial stress $\bar{\sigma}_{x}\left(\frac{L}{2}, z\right)$ through the thickness of the FG sandwich C-F beams for different beam theories and $\mathrm{p}_{z}=1, \mathrm{~L} / \mathrm{h}=5$, Type $\mathrm{B}$. 
Table 17: Dimensionless maximum transverse deflections of the FG sandwich C-F beams for different beam theories and gradation exponents, Type B.

\begin{tabular}{|c|c|c|c|c|c|c|c|c|c|c|c|}
\hline \multirow{3}{*}{ Theory } & \multirow{3}{*}{ ? } & \multicolumn{5}{|c|}{$\mathrm{L} / \mathrm{h}=5$} & \multicolumn{5}{|c|}{$\mathrm{L} / \mathrm{h}=20$} \\
\hline & & \multicolumn{5}{|c|}{$p_{x}$} & \multicolumn{5}{|c|}{$p_{x}$} \\
\hline & & 0 & 0.5 & 1 & 2 & 5 & 0 & 0.5 & 1 & 2 & 5 \\
\hline \multirow{5}{*}{ EBT } & 0 & 27.6273 & 28.1611 & 28.6775 & 29.6519 & 32.0809 & 27.6273 & 28.1611 & 28.6775 & 29.6519 & 32.0809 \\
\hline & 0.5 & 31.6369 & 32.1602 & 32.6618 & 33.5972 & 35.8767 & 31.6369 & 32.1602 & 32.6618 & 33.5972 & 35.8767 \\
\hline & 1 & 34.1584 & 34.6497 & 35.1175 & 35.9819 & 38.0538 & 34.1584 & 34.6497 & 35.1175 & 35.9819 & 38.0538 \\
\hline & 2 & 37.3358 & 37.7618 & 38.1636 & 38.8971 & 40.6171 & 37.3358 & 37.7618 & 38.1636 & 38.8971 & 40.6171 \\
\hline & 5 & 41.9504 & 42.2487 & 42.5263 & 43.0245 & 44.1588 & 41.9504 & 42.2487 & 42.5263 & 43.0245 & 44.1588 \\
\hline \multirow{5}{*}{ TBT } & 0 & 28.7805 & 29.3357 & 29.8715 & 30.8793 & 33.3758 & 27.6955 & 28.2306 & 28.7481 & 29.7243 & 32.1567 \\
\hline & 0.5 & 33.0852 & 33.6308 & 34.1527 & 35.1224 & 37.4701 & 31.7238 & 32.2484 & 32.7511 & 33.6883 & 35.9715 \\
\hline & 1 & 35.8192 & 36.3326 & 36.8201 & 37.7178 & 39.8553 & 34.2588 & 34.7514 & 35.2203 & 36.0865 & 38.1620 \\
\hline & 2 & 39.2824 & 39.7284 & 40.1480 & 40.9114 & 42.6894 & 37.4544 & 37.8815 & 38.2843 & 39.0195 & 40.7427 \\
\hline & 5 & 44.3015 & 44.6144 & 44.6047 & 45.4242 & 46.5988 & 42.0946 & 42.3937 & 42.6719 & 43.1714 & 44.3080 \\
\hline \multirow{5}{*}{ RBT } & 0 & 29.3533 & 29.8945 & 30.4153 & 31.3990 & 33.8458 & 27.7318 & 28.2658 & 28.7823 & 29.7569 & 32.1860 \\
\hline & 0.5 & 33.9443 & 34.4706 & 34.9761 & 35.9174 & 38.2037 & 31.7782 & 32.3015 & 32.8030 & 33.7383 & 36.0176 \\
\hline & 1 & 36.9471 & 37.4387 & 37.9092 & 38.7737 & 40.8473 & 34.3301 & 34.8213 & 35.2890 & 36.1532 & 38.2244 \\
\hline & 2 & 40.8557 & 41.2812 & 41.6811 & 42.4116 & 44.1180 & 37.5540 & 37.9796 & 38.3811 & 39.1142 & 40.8331 \\
\hline & 5 & 46.6402 & 46.9342 & 47.2066 & 47.6940 & 48.8081 & 42.2425 & 42.5403 & 42.8174 & 43.3150 & 44.4477 \\
\hline
\end{tabular}

Table 18: Dimensionless maximum transverse deflections of the FG sandwich C-F beams for different beam theories and gradation exponents, Type $\mathrm{C}$.

\begin{tabular}{|c|c|c|c|c|c|c|c|c|c|c|c|}
\hline \multirow{3}{*}{ Theory } & \multirow{3}{*}{$P_{z}$} & \multicolumn{5}{|c|}{$\mathrm{L} / \mathrm{h}=5$} & \multicolumn{5}{|c|}{$\mathrm{L} / \mathrm{h}=20$} \\
\hline & & \multicolumn{5}{|c|}{$p_{x}$} & \multicolumn{5}{|c|}{$p_{x}$} \\
\hline & & 0 & 0.5 & 1 & 2 & 5 & 0 & 0.5 & 1 & 2 & 5 \\
\hline \multirow{5}{*}{ EBT } & 0 & 96.5367 & 86.1276 & 79.1067 & 69.7789 & 55.7930 & 96.5367 & 86.1276 & 79.1067 & 699.7789 & 55.7930 \\
\hline & 0.5 & 59.5532 & 56.2782 & 53.7373 & 49.9578 & 43.4508 & 59.5532 & 56.2782 & 53.7373 & 49.9578 & 43.4508 \\
\hline & 1 & 48.7588 & 46.9283 & 45.4372 & 43.1173 & 38.8766 & 48.7588 & 46.9283 & 45.4372 & 43.1173 & 38.8766 \\
\hline & 2 & 40.3978 & 39.4581 & 38.6605 & 37.3681 & 34.8659 & 40.3978 & 39.4581 & 38.6605 & 37.3681 & 34.8659 \\
\hline & 5 & 33.5540 & 33.1840 & 32.8584 & 32.3102 & 31.1863 & 33.5540 & 33.1840 & 32.8584 & 32.3102 & 31.1863 \\
\hline \multirow{5}{*}{ TBT } & 0 & 98.4894 & 87.9761 & 80.8756 & 71.4327 & 57.2638 & 96.6162 & 86.2093 & 79.1887 & 69.8599 & 55.8705 \\
\hline & 0.5 & 61.1394 & 57.8160 & 55.2361 & 51.3974 & 44.7906 & 59.6345 & 56.3587 & 53.8169 & 50.0357 & 43.5256 \\
\hline & 1 & 50.2090 & 48.3475 & 46.8309 & 44.4716 & 40.1622 & 48.8371 & 47.0058 & 45.5140 & 43.1929 & 38.9497 \\
\hline & 2 & 41.7334 & 40.7759 & 39.9633 & 38.6473 & 36.1030 & 40.4726 & 39.5324 & 38.7343 & 37.4411 & 34.4373 \\
\hline & 5 & 34.7918 & 34.4141 & 34.0818 & 33.5229 & 32.3795 & 33.6255 & 33.2552 & 32.9294 & 32.3808 & 31.2561 \\
\hline \multirow{5}{*}{ RBT } & 0 & 98.6595 & 88.2651 & 81.2522 & 71.9409 & 58.0143 & 96.6210 & 86.2251 & 79.2221 & 69.8932 & 55.9192 \\
\hline & 0.5 & 61.4646 & 58.2059 & 55.6724 & 51.9058 & 45.4388 & 59.6543 & 56.3840 & 53.8447 & 50.0685 & 43.5672 \\
\hline & 1 & 50.5982 & 48.7794 & 47.2949 & 44.9893 & 40.7800 & 48.8615 & 47.0332 & 45.5437 & 43.2261 & 38.9893 \\
\hline & 2 & 42.1829 & 41.2488 & 40.4599 & 39.1786 & 36.7034 & 40.5011 & 39.5627 & 38.7661 & 37.4751 & 34.9756 \\
\hline & 5 & 35.3006 & 34.9383 & 34.6163 & 34.0754 & 32.9679 & 33.6579 & 33.2885 & 32.9634 & 32.4159 & 31.2935 \\
\hline
\end{tabular}



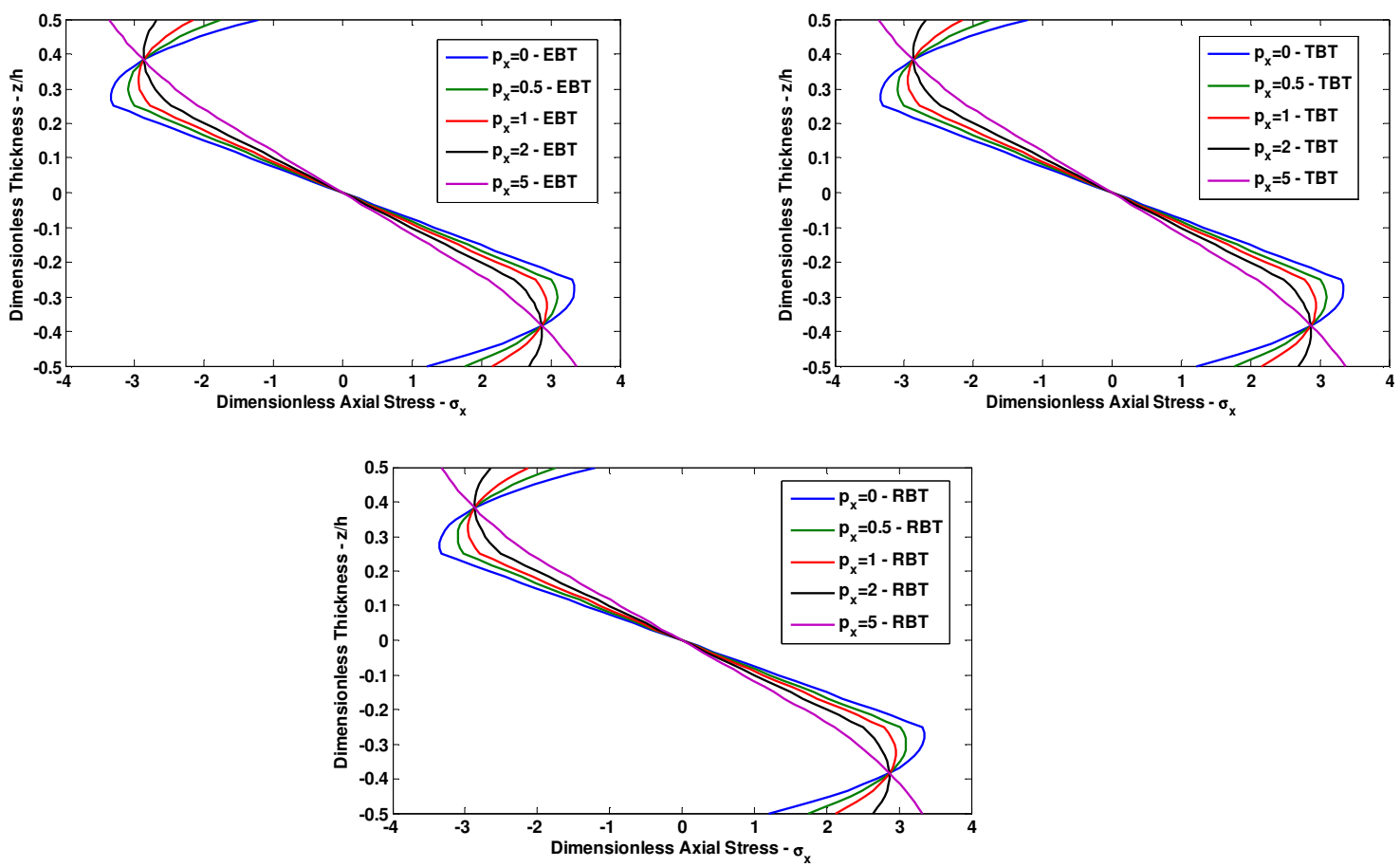

Fig. 17: Dimensionless axial stress $\bar{\sigma}_{x}\left(\frac{L}{2}, z\right)$ through the thickness of the FG sandwich C-F beams for different beam theories and $\mathrm{p}_{z}=1, \mathrm{~L} / \mathrm{h}=5$, Type $\mathrm{C}$. 
TBT

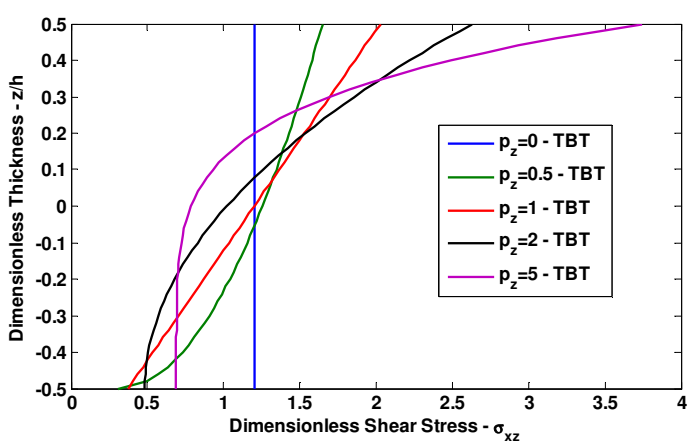

(a)

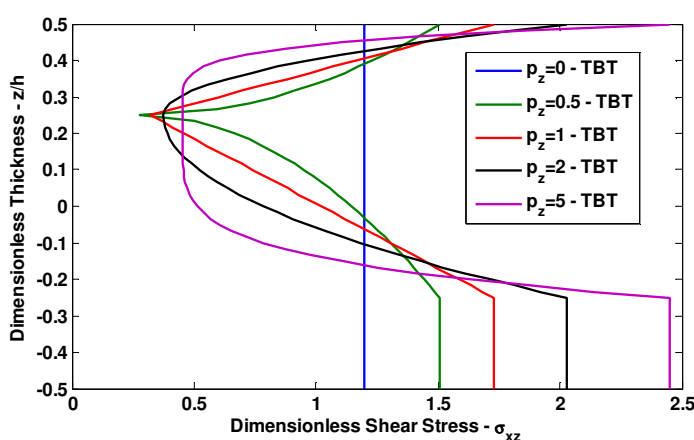

(b)

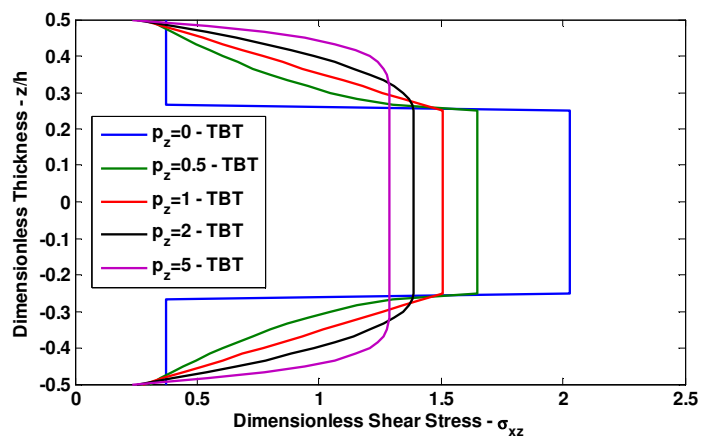

(c)

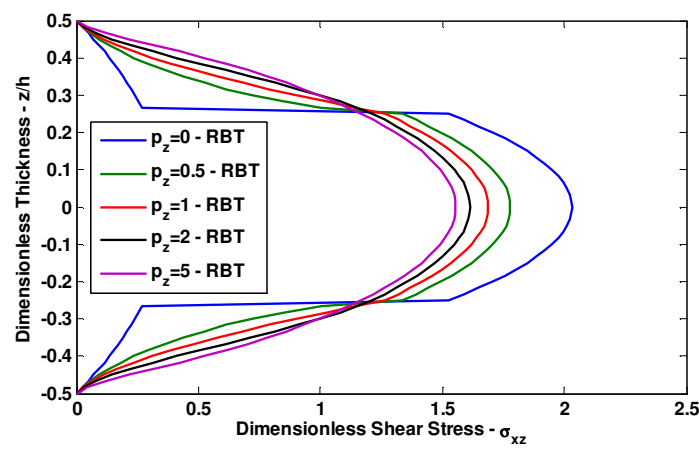

RBT
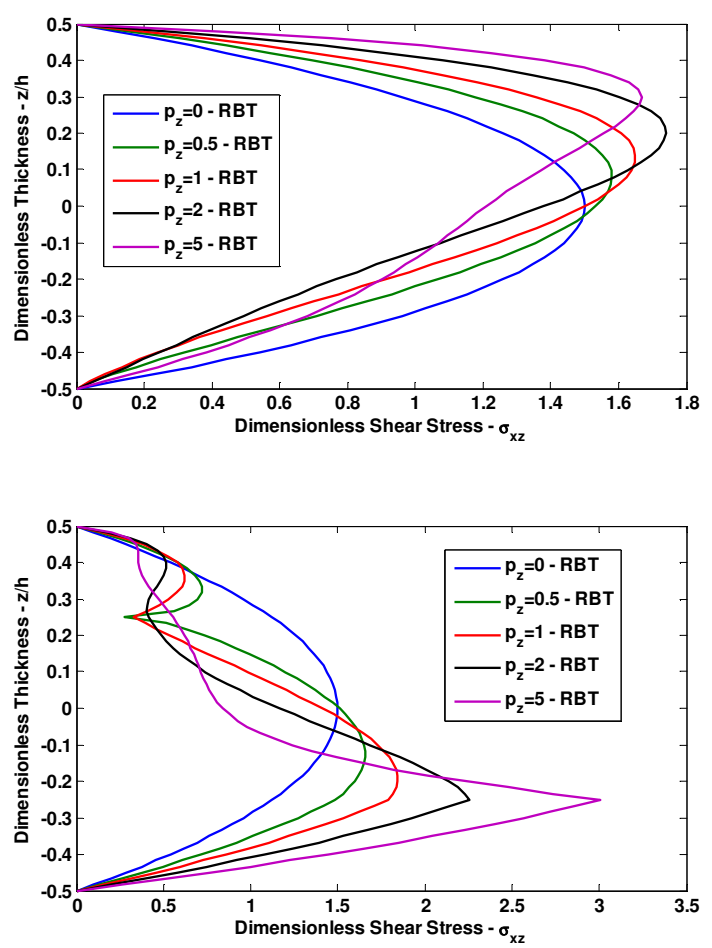

)

Fig. 18: Dimensionless transverse shear stress $\bar{\sigma}_{x z}(0, z)$ through the thickness of the FG sandwich C-F beams for different beam theories and $\mathrm{p}_{x}=1, \mathrm{~L} / \mathrm{h}=5$; a) Type $\left.\mathrm{A}, \mathbf{b}\right)$ Type $\mathrm{B}$, c) Type $\mathrm{C}$. 


\section{Conclusion}

The static behaviour of the two directional functionally graded sandwich beams subjected to different sets of boundary conditions and uniformly distubuted load are investigated by employing the SSPH basis functions and using strong formulation of the problem. The EBT, TBT and RBT formulations are developed regarding to different types of two directional FG sandwich beams to evaluate the transverse deflections, axial and shear stresses. The verification of the developed code is established by solving a conventional FG beam problem and comparing numerical solutions with the results form previous studies and the analytical solutions. The numerical calculations are performed by using 161 nodes uniformly distributed in the problem domain and by employing 7 terms in the TSEs. Various types of sandwich beams are considered. It is clear the results obtained based on the TBT formulation can be more close to ones obtained based on the RBT formulation by choosing the more accurate shear correction factor which depends on the geometry, material properties, loading and boundary conditions.

It is found that the SSPH method provides satisfactory and expected results at least for the problems studied here. Based on the results obtained within the scope of the study, it is recommended that the SSPH method can be applied for solving linear two directional functionally graded sandwich beam problems by employing different shear deformation theories and strong form formulation.

\section{Competing interests}

The authors declare that they have no competing interests.

\section{Authors' contributions}

All authors have contributed to all parts of the article. All authors read and approved the final manuscript.

\section{References}

[1] Sankar BV. An elasticity solution for functionally graded beams. Composites Science and Technology 2001;61:689-696.

[2] Zhong Z, Yu T. Analytical solution of a cantilever functionally graded beam. Composites Science and Technology 2007;67:481488.

[3] Aydogdu M. Thermal buckling analysis of cross-ply laminated composite beams with general boundary conditions. Composite Science and Technology 2007;67:1096-1104.

[4] Ding HJ, Huang DJ, Chen WQ. Elasticity solutions for plane anisotropic functionally graded beams. International Journal of Solids and Structures 2007;44:176-196.

[5] Aydogdu M, Taskin V. Free vibration analysis of functionally graded beams with simply supported edges. Materials\&Design 2007;28:1651-1656.

[6] Kadoli R, Akhtar K, Ganesan N. Static analysis of functionally graded beams using higher order shear deformation theory. Applied Mathematical Modelling 2008;32:2509-2525.

[7] Benatta MA, Mechab I, Tounsi A, Abbas ABE. Static analysis of functionally graded short beams including warping and shear deformation effects. Computational Materials Science 2008;44:765-773.

[8] Li XF. A unified approach for analyzing static and dynamic behaviors of functionally graded Timoshenko and Euler-Bernoulli beams. Journal of Sound and Vibration 2008;318:1210-1229.

[9] Ben-Oumrane S, Tounsi A, Mechab I, Mohamed BB, Mustapha M, Abbas ABE. Theoretical analysis of flexional bending of $\mathrm{Al} / \mathrm{Al}_{2} \mathrm{O}_{3}$ S-FGM thick beams. Computational Materials Science 2009;44:1344-1350.

[10] Sina SA, Navazi HM, Haddadpour H. An analytical method for free vibration analysis of functionally graded beams. Materials\&Design 2009;30:741-747.

[11] Simsek M, Kocaturk T. Free and forced vibration of a functionally graded beam subjected to a concentrated moving harmonic load. Composite Structures 2009;90:465-73. 
[12] Simsek M. Fundamental frequency analysis of functionally graded beams by using different higher-order beam theories. Nuclear Engineering and Design 2010;240:697-705.

[13] Giunta G, Belouettar S, Carrera E. Analysis of FGM beams by means of classical and advanced theories. Mechanics of Advanced Materials and Structures 2010;17:622-635.

[14] Simsek M. Vibration analysis of a functionally graded beam under a moving mass by using different beam theories. Composite Structures 2010;92:904-17.

[15] Mahi A, Adda Bedia EA, Tounsi A, Mechab I. An analytical method for temperature-dependent free vibration analysis of functionally graded beams with general boundary conditions. Composite Structures 2010;92:1877-1887.

[16] Kiani Y, Eslami MR. Thermal buckling analysis of functionally graded material beams. International Journal of Mechanics and Materials in Design 2010;6:229-238.

[17] Aydogdu M. Semi-inverse method for vibration and buckling of axially functionally graded beams. Journal of Reinforced Plastics\&Composites 2008;27:683-691.

[18] Shahba A, Attarnejad R, Marvi MT, Hajilar S. Free vibration and stability analysis of axially functionally graded tapered Timoshenko beams with classical and non-classical boundary conditions. Composites: Part B 2011;42:801-808.

[19] Huang Y, Li XF. Buckling analysis of nonuniform and axially graded columns with varying flexural rigidity. Journal of Engineering Mechanics 2011;137(1):73-81.

[20] Menaa R, Tounsi A, Mouaici F, Mechab I, Zidi M, Bedia EAA. Analytical solutions for static shear correction factor of functionally graded rectangular beams. Mechanics of Advanced Materials and Structures 2012;19:641-652.

[21] Sanjay AK, Gupta RK, Ramachandran P, Venkateswara RG. Free vibration analysis of functionally graded beams. Defence Science Journal 2012;62(3):139-46.

[22] Nuttawit W, Variddhi U. Free vibration analysis of functionally graded beams with general elastically end constraints by DTM. World Journal of Mechanics 2012;2:297-310.

[23] Nateghi A, Salamat-talab M, Rezapour J, Daneshian B. Size dependent buckling analysis of functionally graded micro beams based on modified couple stress theory. Applied Mathematical Modelling 2012;36:4971-4987.

[24] Nie GJ, Zhong Z, Chen S. Analytical solution for a functionally graded beam with arbitrary graded material properties. Composites Part B 2013;44:274-282.

[25] Pradhan KK, Chakraverty S. Free vibration of Euler and Timoshenko functionally graded beams by Rayleigh-Ritz method. Composites Part B 2013:51;175-184.

[26] Li SR, Cao DF, Wan ZQ. Bending solutions of FGM Timoshenko beams from those of the homogenous Euler-Bernoulli beams. Applied Mathematical Modelling 2013;37:7077-7085.

[27] Su H, Banerjee JR, Cheung CW. Dynamic stiffness formulation and free vibration analysis of functionally graded beams. Composite Structures 2013;106:854-862.

[28] Pradhan KK, Chakraverty S. Effects of different shear deformation theories on free vibration of functionally graded beams. International Journal of Mechanical Sciences 2014;82:149-60.

[29] Li SR, Wan ZG, Zhang JH. Free vibration of functionally graded beams based on both classical and first-order shear deformation beam theories. Applied Mathematics and Mechanics 2014;35:591-606.

[30] Filippi M, Carrera E, Zenkour AM. Static analyses of FGM beams by various theories and finite elements. Composites Part B 2015;72:1-9.

[31] Jing LL, Ming PJ, Zhang WP, Fu LR, Cao YP. Static and free vibration analysis of functionally graded beams by combination Timoshenko theory and finite volume method. Composite Structures 2016;138:192-213.

[32] Nemat-Alla M. Reduction of thermal stresses by developing two-dimensional functionally graded materials. International Journal of Solids and Structures 2003;40:7339-7356.

[33] Goupee AJ, Vel SS. Optimization of natural frequencies of bidirectional functionally graded beams. Struct Multidisc Optim 2006;32:473-484.

[34] Lü CF, Chen WQ, Xu RQ, Lim CW. Semi-analytical elasticity solutions for bidirectional functionally graded beams. International Journal of Solids and Structures 2008;45:258-275.

[35] Zhao L, Chen WQ, Lü CF. Symplectic elasticity for two-directional functionally graded materials. Mech Mater 2012;54:32-42.

[36] Simsek M. Buckling of Timoshenko beams composed of two-dimensional functionally graded material (2D-FGM) having different boundary conditions. Composite Structures 2016; 149:304-314. 
[37] Hao D, Wei C. Dynamic characteristics analysis of bi-directional functionally graded Timoshenko beams. Composite Structures 2016;141:253-263.

[38] Karamanli, A. Elastostatic analysis of two-directional functionally graded beams using various beam theories and symmetric smoothed particle hydrodynamics. Composite Structures (Accepted, in press).

[39] Vo TP, Thai HT, Nguyen TK, Inam F, Lee J. Static behaviour of functionally graded sandwich beams using a quasi-3D theory. Composites Part B 2015;68:59-74.

[40] Vo TP, Thai H-T, Nguyen T-K, Inam F, Lee J. A quasi-3D theory for vibration and buckling of functionally graded sandwich beams. Compos Struct 2015;119:1-12.

[41] Mantari JL, Yarasca J. A simple and accurate generalized shear deformation theory for beams. Compos Struct 2015;134:593-601.

[42] Mantari JL. A refined theory with stretching effect for the dynamics analysis of advanced composites on elastic foundation. Mech Mater 2015;86:31-43.

[43] Mantari JL. Refined and generalized hybrid type quasi-3D shear deformation theory for the bending analysis of functionally graded shells. Composites B 2015;83:142-152.

[44] Tossapanon P, Wattanasakulpong N. Stability and free vibration of functionally graded sandwich beams resting on two-parameter elastic foundation. Composite Structures 2016;142:215-225.

[45] Kim N, Lee J. Theory of thin-walled functionally graded sandwich beams with single and double-cell sections. Composite Structures 2016;157:141-154.

[46] Chen D, Kitipornchai S, Yang J.Nonlinear free vibration of shear deformable sandwich beam with a functionally graded porous core. Thin-Walled Structures 2016;107:39-48.

[47] Simsek M, Al-shujairi M. Static, free and forced vibration of functionally graded (FG) sandwich beams excited by two successive moving harmonic loads. Composites Part B 2017;108:18-34.

[48] Osofero AI, Vo TP, Nguyen T-K, Lee J. Analytical solution for vibration and buckling of functionally graded sandwich beams using various quasi-3D theories, J Sandwich Struct Mater; in press.

[49] Zhang GM, Batra RC. Symmetric smoothed particle hydrodynamics (SSPH) method and its application to elastic problems. Computational Mechanics 2009;43:321-340.

[50] Batra RC, Zhang GM. SSPH basis functions for meshless methods, and comparison of solutions with strong and weak formulations. Computional Mechanics 2008;41:527-545.

[51] Tsai CL, Guan YL, Batra RC, Ohanehi DC, Dillard JG, Nicoli E, Dillard DA. Comparison of the performance of SSPH and MLS basis functions for two-dimensional linear elastostatics problems including quasistatic crack propagation. Computational Mechanics, 2013;51:19-34.

[52] Tsai CL, Guan YL, Ohanehi DC, Dillard JG, Dillard DA, Batra RC. Analysis of cohesive failure in adhesively bonded joints with the SSPH meshless method. International Journal of Adhesion \& Adhesives 2014;51:67-80.

[53] Karamanli A, Mugan A. Solutions of two-dimensional heat transfer problems by using symmetric smoothed particle hydrodynamics method. Journal of Applied and Computational Mathematics 2012;1:1-6.

[54] Karamanli A. Bending Deflection Analysis of a Semi-Trailer Chassis by Using Symmetric Smoothed Particle Hydrodynamics. International Journal of Engineering Technologies 2015;Vol.1;No:4:134-140.

[55] Li XF, Wang BL, Han JC. A higher-order theory for static and dynamic analyses of functionally graded beams. Archieve of Applied Mechanics 2010;80:1197-1212. 